\title{
The Hydrothermal Chemistry of Gold, Arsenic, Antimony, Mercury and Silver
}

\author{
Brad Bessinger \\ Exponent, Inc. \\ 5335 Meadows Road, Suite 365 \\ Lake Oswego, OR 97035 \\ John A. Apps \\ Earth Sciences Division \\ Lawrence Berkeley National Laboratory \\ University of California, Berkeley, California 94720
}

March 2005

This work was supported by the Director, Office of Science

Office of Basic Energy Sciences of the U.S. Department of Energy under Contract No. DE-AC03-76SF00098. 


\begin{abstract}
A comprehensive thermodynamic database based on the Helgeson-Kirkham-Flowers (HKF) equation of state was developed for metal complexes in hydrothermal systems. Because this equation of state has been shown to accurately predict standard partial molal thermodynamic properties of aqueous species at elevated temperatures and pressures, this study provides the necessary foundation for future exploration into transport and depositional processes in polymetallic ore deposits. The HKF equation of state parameters for gold, arsenic, antimony, mercury, and silver sulfide and hydroxide complexes were derived from experimental equilibrium constants using nonlinear regression calculations. In order to ensure that the resulting parameters were internally consistent, those experiments utilizing incompatible thermodynamic data were re-speciated prior to regression. Because new experimental studies were used to revise the HKF parameters for $\mathrm{H}_{2} \mathrm{~S}^{0}$ and $\mathrm{HS}^{-1}$, those metal complexes for which HKF parameters had been previously derived were also updated. It was found that predicted thermodynamic properties of metal complexes are consistent with linear correlations between standard partial molal thermodynamic properties. This result allowed assessment of several complexes for which experimental data necessary to perform regression calculations was limited.

Oxygen fugacity-temperature diagrams were constructed from predicted thermodynamic properties to illustrate how thermodynamic data can be used to understand the transport and deposition of metals in hydrothermal systems such as the Carlin-type gold deposits. Assuming a linear relationship between temperature and pressure, metals are predicted to predominantly be transported as sulfide complexes at a total aqueous sulfur concentration of $0.05 \mathrm{~m}$. Also, the presence of arsenic and antimony mineral phases in the deposits are shown to restrict mineralization within a limited range of chemical conditions. Finally, at a lesser aqueous sulfur concentration of $0.01 \mathrm{~m}$, host rock sulfidation can explain the origin of arsenic and antimony minerals within the paragenetic sequence.
\end{abstract}




\section{Introduction}

One important source of clues to the origin of metallic ore deposits is the suite of metals associated with mineralization. This is because the co-transport and deposition of metals such as gold, arsenic, antimony, mercury, and silver invariably reduces the number of possible ore-forming processes to those consistent with mineral phases containing those metals. For example, an accurate description of ore formation in Carlin-type gold deposits must account for the fact that precipitation and adsorption reactions involving gold are invariably tied to the solubility of arsenic (Arehart et al., 1993; Simon et al., 1999). Models of deposition must also be consistent with observed paragenetic sequencing of minerals, such as late-stage realgar and orpiment (Arehart, 1996). Finally, models must account for differences in gold, silver, and mercury concentrations between deposits (Bagby and Berger, 1985).

The objective of this study was to develop a consistent thermodynamic database applicable to modeling aqueous metal transport under hydrothermal conditions. The partial molal thermodynamic properties discussed in the text were derived using the Helgeson-Kirkham-Flowers (HKF) equation of state (Helgeson et al., 1981; Tanger and Helgeson, 1988). This equation of state was selected because it has been shown to accurately predict geochemical reactions at elevated temperatures and pressures (Shock et al., 1992).

This study was preceded by investigations which have derived HKF equation of state parameters for several metal sulfide and hydroxide complexes believed to contribute to metal solubility (Akinfiev et al., 1992; Akinfiev et al., 1994; Pokrovski et al., 1996; Sverjensky et al., 1997; Zotov et al., 2003; Akinfiev and Zotov, 2001). The revisions and refinements of this investigation are

necessitated by the fact that experimental evidence provided by Sulemeinov and Krupp (1994) and 
Sulemeinov and Seward (1997) indicate that the Henry and first ionization constants of $\mathrm{H}_{2} \mathrm{~S}$ used to calculate previous experimental equilibrium constants and equation of state parameters are incorrect. Also, for the case of arsenic sulfide complexes, Akinfiev et al. (1992) developed parameters assuming that the stable complexes are dimers, although many lines of evidence now support the existence of trimeric species (Eary, 1992; Helz, et al, 1995). Systematic correlations between standard partial molal thermodynamic properties have not been developed for some species, even though trends for other ions and complexes have been identified (Shock and Helgeson, 1988; Shock et al., 1997).

Finally, there are aqueous metal complexes important to modeling hydrothermal ore deposits missing from the current compilation of HKF equation of state parameters.

The HKF equation of state and the least square regression techniques employed in this study are described in the first section of the paper. This is followed by a discussion of HKF of state parameters for aqueous sulfide and hydroxide species and complexes. Using predicted standard partial molal Gibbs free energies of formation, fugacity-temperature diagrams are used to illustrate important aqueous and mineral phases in the Carlin-type gold deposits, and highlight potential ore forming processes.

\section{Description of Methods}

\section{Calculated experimental solubility constants}

Laboratory solubility experiments described below were re-speciated to obtain revised solubility constants using predicted standard partial molal Gibbs free energies for $\mathrm{H}_{2} \mathrm{~S}^{0}$ and $\mathrm{HS}^{-1}$ calculated in this study. The methods used to perform speciation were the same as those selected in the original investigations. Most involved assigning experimental results to a particular metal complex and subsequently iterating over the mass action, mass balance, and charge balance equations to achieve convergence of the solution. For gold and silver sulfide complexes this was accomplished numerically, using the computer speciation software Selektor-A (Kulik et al., 1997), which 
incorporates the SUPCRT database, uses a convex programming technique to minimize the Gibbs function, and calculates activity coefficients in a manner analogous to Helgeson et al. (1981). This particular code was selected because it encompasses the full range of conditions available to the HKF equation of state (up to $1000^{\circ} \mathrm{C}$ and 5000 bars), and thus allowed re-speciation of experiments that were performed at elevated temperatures and pressures.

\section{Summary of regression calculations}

The HKF equation of state describes standard partial molal thermodynamic properties of aqueous species at elevated temperatures and pressures in terms of electrostatic and non-electrostatic interactions between aqueous species and solution. It is the only model currently available that is capable of predicting reaction constants at the elevated pressures inferred for the Carlin-type gold deposits. Properties are expressed as functions of the dielectric properties of the solvent and solute using nine species-dependent constants, which can be obtained directly from experimental data through regression calculations, or in cases where data are insufficient, linear correlations between properties. As shown in this study, there may be large uncertainities inherent in the use of correlations.

Regression calculations were used to obtain the following nine HKF equation of state parameters required to predict the standard partial molal Gibbs free energies of formation of aqueous complexes $\left[\Delta \bar{G}_{c}^{o}\right]$ at elevated temperatures and pressures: $\left[\Delta \bar{G}_{f_{\mathrm{Pr}, T r}}^{o}\right] ;\left[\bar{S}_{\mathrm{Pr}, T r}^{o}\right] ;\left[c_{1}\right] ;\left[c_{2}\right] ;\left[a_{1}\right] ;\left[a_{2}\right]$; $\left[a_{3}\right] ;\left[a_{4}\right]$; and $\left[\omega_{\mathrm{Pr}, T r}\right]$ (Helgeson et al., 1981; Tanger and Helgeson, 1988). First, $\left[\Delta \bar{G}_{c}^{o}\right]$ was calculated from experimental solubility experiments using the following equation:

$$
\Delta \bar{G}_{c}^{o}=2.303 R T \log K_{r}+\sum_{i} \hat{n}_{i, c} \Delta \bar{G}_{i}^{o}+\sum_{j} \hat{n}_{j} \Delta G_{j}^{o}
$$

where $\left[K_{r}\right]$ is the experimental equilibrium constant, $\left[\hat{n}_{i, c}\right]$ and $\left[\Delta \bar{G}_{i}^{o}\right]$ are the stoichiometric reaction coefficient and standard partial molal Gibbs free energy for the $i$ th aqueous species obtained 
from SUPCRT or this study, and $\left[\hat{n}_{j}\right]$ and $\left[\Delta G_{j}^{o}\right]$ are the stoichiometric reaction coefficient and standard Gibbs free energy for the $j$ th mineral from Table 1.

For $\mathrm{HS}^{-1}$, the following regression equations were used, based on the availability of temperature-dependent standard partial molal Gibbs free energy, volume, and heat capacity experiments:

$$
\begin{aligned}
& \Delta \bar{G}^{o}=\Delta \bar{G}_{f_{\mathrm{P}, T r}}^{o}-\bar{S}_{\mathrm{Pr}, T r}^{o}\left(T-T_{r}\right)-c_{1}\left(T \ln \left(\frac{T}{T_{r}}\right)-T+T_{r}\right) \\
& -c_{2}\left(\left\lceil\left(\frac{1}{T-\theta}\right)-\left(\frac{1}{T_{r}-\theta}\right)\right]\left(\frac{\theta-T}{\theta}\right)-\frac{T}{\theta^{2}} \ln \left\lceil\frac{T_{r}(T-\theta)}{T\left(T_{r}-\theta\right)}\right\rfloor\right) \\
& +a_{1}\left(P-P_{r}\right)+a_{2} \ln \left(\frac{\Psi+P}{\Psi+P_{r}}\right)+a_{3}\left(\frac{P-P_{r}}{T-\theta}\right)+a_{4}\left(\frac{1}{T-\theta}\right) \ln \left(\frac{\Psi+P}{\Psi+P_{r}}\right) \\
& +\omega_{\operatorname{Pr}, T r}\left\lceil\frac{1}{\varepsilon}-\frac{1}{\varepsilon_{\operatorname{Pr} T r}}+Y_{\operatorname{Pr}, T r}\left(T-T_{r}\right)\right]+k\left[\omega-\omega_{\operatorname{Pr}, T r}\right]\left(\frac{1}{\varepsilon}-1\right) \\
& \bar{V}^{o}=a_{1}+a_{2}\left(\frac{1}{\Psi+P}\right)+\left(a_{3}+a_{4}\left(\frac{1}{\Psi+P}\right)\right)\left(\frac{1}{T-\theta}\right)-\omega Q+\left(\frac{1}{\varepsilon}-1\right)\left(\frac{\partial \omega}{\partial P}\right)_{T} \\
& \bar{C}_{P}^{o}=c_{1}+\frac{c_{2}}{(T-\theta)^{2}}-\left(\frac{2 T}{(T-\theta)^{3}}\right)\left(a_{3}\left(P-P_{r}\right)+a_{4} \ln \left(\frac{\Psi+P}{\Psi+P_{r}}\right)\right) \\
& +\omega T X+2 T Y\left(\frac{\partial \omega}{\partial T}\right)_{P}-T\left(\frac{1}{\varepsilon}-1\right)\left(\frac{\partial^{2} \omega}{\partial T^{2}}\right)
\end{aligned}
$$


Table 1. Thermodynamic Properties of Solid Phases Used In This Study

\begin{tabular}{|c|c|c|c|c|c|c|c|c|}
\hline Solid phase $^{\mathrm{f}}$ & $\Delta_{\mathrm{f}} \mathrm{G}^{\circ}{ }_{290}{ }^{\mathrm{a}}$ & $S_{298}{ }^{o b}$ & $\mathrm{C}_{\mathrm{p} 298^{\circ \mathrm{b}}}$ & $\mathrm{V}_{298^{\circ}}$ & $\mathbf{a}^{\mathbf{b}}$ & $\mathbf{b}^{\mathrm{d}} \times 10^{-3}$ & $c^{\mathrm{e}} \times 10^{5}$ & Reference \\
\hline $\mathrm{As}_{2} \mathrm{O}_{3}$ (arsenolite) & -137640 & 25.67 & 23.15 & 51.12 & 20.98 & 17.73 & -2.70 & Pokrovski et al. (1996) \\
\hline $\mathbf{A s}_{2} \mathbf{O}_{3}$ (claudetite) & -137730 & 27.09 & 23.19 & 47.26 & 23.86 & 10.74 & -3.44 & Pokrovski et al. (1996) \\
\hline $\mathbf{A s}_{2} \mathbf{S}_{3}$ (orpiment) & -20550 & 39.10 & 27.53 & 70.50 & 22.73 & 13.82 & 0.605 & Pokrovski et al. (1996) \\
\hline As (arsenic) & 0 & 8.39 & 5.89 & 12.96 & 5.23 & 2.22 & 0 & Pokrovski et al. (1996) \\
\hline AsS (realgar) & -7930 & 12.96 & 11.37 & 29.8 & 12.94 & -0.0133 & 1.396 & Pokrovski et al. (1996) \\
\hline $\mathrm{FeAs}_{2}$ (loellingite) & -12450 & 30.4 & 11.05 & 27.51 & 5.4 & 7.3 & 0 & Pokrovski et al. (1996) \\
\hline FeAsS (arsenopyrite) & -30000 & 25.9 & 17.6 & 26.42 & 15.03 & 9.7 & 0.34 & Pokrovski et al. (2000) \\
\hline Sb (native antimony) & 0 & 10.773 & 6.05 & 18.178 & 2.49 & 5.93 & 1.88 & Akinfiev et al. (1994) \\
\hline $\mathrm{Sb}_{2} \mathrm{O}_{3}$ (senarmontite) & -151400 & 27.37 & 22.54 & 52.21 & 22.53 & 12.03 & -3.179 & Zotov et al. $(2003)^{\mathrm{h}}$ \\
\hline $\mathrm{Sb}_{2} \mathrm{O}_{3}$ (valentite) & -149600 & 29.43 & 24.29 & 50.01 & 24.840 & 10.2 & -3.197 & Zotov et al. $(2003)^{\mathrm{h}}$ \\
\hline $\mathbf{S b}_{2} \mathrm{~S}_{3}$ (stibnite) & -35846 & 43.50 & 28.60 & 73.414 & 28.75 & 3.927 & -1.264 & Zotov et al. $(2003)^{\mathrm{h}}$ \\
\hline $\mathrm{FeSb}_{2} \mathrm{~S} 4$ (berthierite) & -61176 & 58.56 & 51.0 & $90.6^{\mathrm{i}}$ & 46.59 & 0.263 & -3.86 & Seal et al. (1992) \\
\hline HgO (montroydite) & -13998 & 16.8 & 10.5 & 19.32 & 8.33 & 7.37 & 0 & Naumov et al. (1974) \\
\hline $\mathrm{Ag}_{2} \mathrm{O}$ & -2676 & 29 & 15.7 & $30^{\mathrm{i}}$ & 11.13 & 15.48 & 0 & Naumov et al. (1974) \\
\hline $\operatorname{Ag}_{2} \mathrm{~S}$ (argentite) & -9450 & 36 & 21.6 & 34.8 & 21.64 & 0 & 0 & Naumov et al. (1974) \\
\hline
\end{tabular}

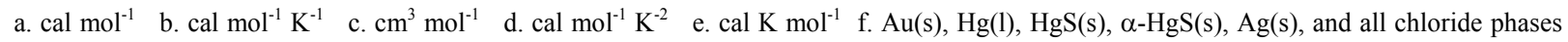
from Johnson et al. (1992) g. Fe-Sb-S-O minerals from Williams-Jones and Normand (1997) after applying pressure correction to reported log $\mathrm{K}_{\mathrm{r}}$ for pressure h Heat capacity data re-derived in terms of Maier and Kelley (1932) heat capacity function i. Estimated parameter 
where $[k]$ is a switch function equal to 1 for charged species and 0 for neutral species (Sverjensky et al., 1997), and $[Q],[Y]$, and $[X]$ are given by:

$$
\begin{aligned}
& Q \equiv-\left(\frac{\partial(1 / \varepsilon)}{\partial P}\right)_{T}=\frac{1}{\varepsilon^{2}}\left(\frac{\partial \varepsilon}{\partial P}\right)_{T} \\
& Y \equiv-\left(\frac{\partial(1 / \varepsilon)}{\partial T}\right)_{P}=\frac{1}{\varepsilon^{2}}\left(\frac{\partial \varepsilon}{\partial T}\right)_{P} \\
& X \equiv\left(\frac{\partial Y}{\partial T}\right)_{P}=\frac{1}{\varepsilon^{2}}\left(\left(\frac{\partial^{2} \varepsilon}{\partial T^{2}}\right)_{P}-\frac{2}{\varepsilon}\left(\frac{\partial \varepsilon}{\partial T}\right)_{P}^{2}\right)
\end{aligned}
$$

(Tanger and Helgeson, 1988) and can be computed from equations expressing the dielectric properties of water to $1000^{\circ} \mathrm{C}$ and $5 \mathrm{kbar}$ (Johnson and Norton, 1992).

For metal complexes where heat capacity and volume measurements are not available, it has been found that many HKF equation of state parameters are linearly correlated and the number of regression parameters can be reduced. These correlations are numerous and are summarized in Shock and Helgeson (1988), Shock et al. (1989), Sverjensky et al. (1997), and Shock et al. (1997). The correlations which were used most extensively in the calculations of this study are:

$$
\begin{aligned}
& \sigma=(1.11) \Delta \bar{V}_{n, \operatorname{Pr}, T r}^{o}+1.8 ; \\
& a_{1}=(0.013684) \Delta \bar{V}_{n, \operatorname{Pr}, T r}^{o}+0.1765 ; \\
& a_{4}=-(4.134) a_{2}-27790 ; \\
& c_{2}=(2037) \bar{C}_{\operatorname{Pr}, T r}^{o}-30460 ;
\end{aligned}
$$

where

$$
\begin{aligned}
& \Delta \bar{V}_{n, \operatorname{Pr}, T r}^{o}=\bar{V}_{\mathrm{Pr}, T r}^{o}+\omega_{\mathrm{Pr}, T r} Q_{\mathrm{Pr}, T r} ; \text { and } \\
& \sigma=a_{1}+\frac{a_{2}}{\Psi+P_{r}} .
\end{aligned}
$$


Following Sverjensky et al. (1997), these correlations can be combined with equations (2) and (3) to give:

$$
\begin{aligned}
& \Delta \bar{G}^{o}=\Delta \bar{G}_{f_{\mathrm{Pr}, T r}}^{o}-\bar{S}_{\mathrm{Pr}, T r}^{o}\left(T-T_{r}\right)-\bar{C}_{\mathrm{Pr}, T r}^{o}\left[(0.5861)\left(T \ln \left(\frac{T}{T_{r}}\right)-T+T_{r}\right)\right] \\
& \left.-\bar{C}_{\mathrm{Pr}, T r}^{o}\left\lceil(2037)\left(\left[\left(\frac{1}{T-\theta}\right)-\left(\frac{1}{T_{r}-\theta}\right)\right]\left(\frac{\theta-T}{\theta}\right)-\frac{T}{\theta^{2}} \ln \left[\frac{T_{r}(T-\theta)}{T\left(T_{r}-\theta\right)}\right\rceil\right]\right)\right] \\
& +\bar{V}_{\mathrm{Pr}, T r}^{o}\left\lceil(0.0137)\left(P-P_{r}\right)+(33.412) \ln \left(\frac{\Psi+P}{\Psi+P_{r}}\right)+(-0.1313)\left(\frac{P-P_{r}}{T-\theta}\right)\right] \\
& +\bar{V}_{\mathrm{Pr}, T r}^{o}\left\lceil(-138.13)\left(\frac{1}{T-\theta}\right) \ln \left(\frac{\Psi+P}{\Psi+P_{r}}\right)\right]+\omega_{\mathrm{Pr}, T r}\left[T X\left(T \ln \left(\frac{T}{T_{r}}\right)-T+T_{r}\right)\right] \\
& \left.+\omega_{\mathrm{Pr}, T r}\left[(41.8393 Q)\left[(0.013684)\left(P-P_{r}\right)+(33.412)\left(\ln \left(\frac{\Psi+P}{\Psi+P_{r}}\right)\right)\right]\right\rceil\right] \\
& +\omega_{\mathrm{Pr}, T r}\left[(41.8393 Q)\left\lceil(-0.1313)\left(\frac{P-P_{r}}{T-\theta}\right)+(-138.13)\left(\left(\frac{1}{T-\theta}\right) \ln \left(\frac{\Psi+P}{\Psi+P_{r}}\right)\right)\right]\right\rceil \\
& +\omega_{\mathrm{Pr}, T r}\left\lceil\left(\frac{1}{\varepsilon}-\frac{1}{\varepsilon_{\mathrm{Pr}, T r}}+Y_{\mathrm{Pr}, T r}\left(T-T_{r}\right)\right)\right\rceil+(-6.16)\left(T \ln \left(\frac{T}{T_{r}}\right)-T+T_{r}\right) \\
& +(30346)\left(\left[\left(\frac{1}{T-\theta}\right)-\left(\frac{1}{T_{r}-\theta}\right)\right]\left(\frac{\theta-T}{\theta}\right)-\frac{T}{\theta^{2}} \ln \left[\frac{T_{r}(T-\theta)}{T\left(T_{r}-\theta\right)}\right]\right)+(0.1765)\left(P-P_{r}\right) \\
& +(-347.18)\left(\ln \left(\frac{\Psi+P}{\Psi+P_{r}}\right)\right)+(7.1146)\left(\frac{P-P_{r}}{T-\theta}\right)+(-26355)\left(\left(\frac{1}{T-\theta}\right) \ln \left(\frac{\Psi+P}{\Psi+P_{r}}\right)\right) \\
& +k\left[\omega-\omega_{\mathrm{Pr}, T r}\right]\left(\frac{1}{\varepsilon}-1\right) .
\end{aligned}
$$

Equation (14) differs slightly from equation (38) of Sverjensky et al. (1997), but independent calculation of $\left[\Delta \bar{G}^{o}\right]$ using equation (2) verifies that equation (14) is correct. Of most importance to this study is the fact that utilization of equation (14) allows the number of regression parameters to be 
reduced from nine to five. Also, for experimental data below 200 bars, the pressure terms contribute negligibly to $\left[\Delta \bar{G}^{o}\right]$ and the number of regression parameters in equation (14) can be further reduced to four (Sverjensky et al., 1997). Finally, correlations between the parameters in equation (14) can be used in cases where experimental data are limited.

An important implication of using equation (14) to determine the HKF equation of state parameters is that the Born parameter for charged species at the reference temperature and pressure $\left[\omega_{\mathrm{Pr}, T r}\right]$ cannot be regressed because it is dependent on $\left[\bar{S}_{\mathrm{Pr}, T r}^{o}\right]$. This dependence is due to the fact that for the $j$ th charged species the Born parameter $[\omega]$ must be calculated from:

$$
\omega_{j}=\eta Z_{j}\left\lfloor\frac{Z_{j}}{r_{e, j, \operatorname{Pr}, T r}+|Z| g}-\frac{1}{3.08+g}\right\rceil
$$

where $[\eta]$ is a constant, $\left[Z_{j}\right]$ is the charge on the species, and the effective electrostatic radius $\left[r_{e, j, \mathrm{Pr}, T r}\right]$ is correlated to $\left[\bar{S}_{\mathrm{Pr}, T r}^{o}\right]$ via:

$$
r_{e, j, \operatorname{Pr}, T r}=\frac{Z_{j}^{2}\left(\eta Y_{\mathrm{Pr}, T r}-100\right)}{\bar{S}_{\mathrm{Pr}, T r}^{o}-\alpha_{Z}}
$$

and where $\left[\alpha_{Z}\right]$ is a charge-dependent correlation parameter equal to $71.5\left|Z_{j}\right|$ (Shock and Helgeson, 1988). An alternative regression approach would have been to express equation (14) explicitly in terms of the effective radius of the charged species at the reference temperature and pressure $\left[r_{e, j, \mathrm{Pr}, T r}\right]$; however, this method was neither adopted by Sverjensky et al. (1997) nor used in the regression calculations of this study. The correlation between $\left[\omega_{\mathrm{Pr}, T r}\right]$ and $\left[\bar{S}_{\mathrm{Pr}, T r}^{o}\right]$ was calculated from equations (15) and (16) to be:

$$
\omega_{j \mathrm{Pr}, T r}=-1514.2 \bar{S}_{\mathrm{Pr}, T r}^{o}+\beta_{Z}
$$

where $\left[\beta_{Z}\right]$ is a charge-dependent constant which again differs slightly from the values reported by Sverjensky et al. (1997). 
The errors associated with the regression calculations are reported as two standard deviations. The explanation why many error envelopes are shown to be less than the uncertainty associated with any particular datum is that only the mean value of an experimental run was used in the regression calculations. Consequently, the error envelopes shown on the following figures only represent the uncertainty in the fits to the mean data.

\section{Aqueous Sulfur Species}

$\mathrm{H}_{2} \mathrm{~S}^{0}$

The HKF equation of state parameters derived by Shock et al. (1989) do not adequately characterize the standard partial molal volume or heat capacity of $\mathrm{H}_{2} \mathrm{~S}^{0}$ measured by Hnedkovsky et al. (1996) and Hnedkovsky and Wood (1997), respectively. Consequently, Plyasunov et al. (2000)

developed an alternative equation of state for neutral, volatile species. The $\left[\Delta \bar{G}_{i}^{o}\right]$ predicted by this model for $\mathrm{H}_{2} \mathrm{~S}^{0}$ at temperatures and pressures above the water vapor saturation curve were used in this study.

Because Plyasunov et al. (2000) elected to use the experimental studies of Drummond (1981) and Kozintseva (1964) for the reaction:

$$
\mathrm{H}_{2} \mathrm{~S}(\mathrm{~g})=\mathrm{H}_{2} \mathrm{~S}^{0}
$$

along the water vapor saturation curve, and because both Drummond (1981) and Kozintseva (1964) utilized stainless steel autoclaves in their experiments, with the former reporting the formation of iron sulfide and hydrogen gas due to corrosion of the vessel, it is likely that the Henry constants predicted by their model are overestimated in this temperature and pressure regime. Consequently, the HKF equation of state parameters were re-computed in this study for use along the water vapor phase boundary utilizing the Henry constant data of Suleimenov and Krupp (1994) (who employed a titanium autoclave with gold coated seals and gaskets). 
The first step in the calculations of this revision was to obtain $\left[c_{2}\right]$ and $[\omega]$ from equations (1) and (2) using the values of Shock et al. (1989) for all of the other equation of state parameters (these two parameters were selected because they were found to be the most sensitive at the highest temperatures where a modification was required). Next, $\left[a_{1}\right]$ through $\left[a_{4}\right]$ were re-computed in a manner analogous to Shock et al. (1989) utilizing the updated value of $[\omega]$. Predictions of $\left[\Delta \bar{G}_{f}^{o}\right]$, $\left[\bar{V}^{o}\right]$, and $\left[\bar{C}_{\mathrm{Pr}}^{o}\right]$ based on the revised equation of state parameters are reported in Table 2. Figure 1A shows that the resultant predictions differ by $0.1 \log$ units from Plyasunov et al. (2000) for the $\log \mathrm{K}_{\mathrm{r}}$ of reaction $(18)$ at $350^{\circ} \mathrm{C}$ and $\mathrm{P}_{\text {sat }}$.

$H S^{-1}$

The HKF equation of state parameters for $\mathrm{HS}^{-1}$ were originally derived by Shock and Helgeson (1988) using the heat capacity and volumetric measurements of Barbero et al. (1982) and the volumetric measurements of Ellis and McFadden (1972). Predictions using their $\left[\Delta \bar{G}_{i}^{o}\right]$ for $\mathrm{HS}^{-1}$ from the equilibrium constant for the following reaction:

$$
\mathrm{H}_{2} \mathrm{~S}^{0}=\mathrm{H}^{+}+\mathrm{HS}^{-1}
$$

produce results consistent with the measurements to $150^{\circ} \mathrm{C}$ of Kryukov and Starostina (1978), Tsonopoulos et al. (1976), and Sretenskaya (1977), Ellis and Giggenbach (1971), and Suleimenov and Seward (1997); however, results deviate from the two studies which measured the equilibrium constant for reaction (19) at higher temperatures (Ellis and Giggenbach, 1971 and Suleimenov and Seward, 1997). Although the results of Ellis and Giggenbach (1971) are suspect because their equilibrium constant for reaction (19) exhibits an inversion of curvature inconsistent with an increasing degree of association observed for most ions at higher temperatures, there are no clear reasons for dismissing the 0.4 logarithmic difference at $350^{\circ} \mathrm{C}$ between Shock and Helgeson (1988) and Suleimenov and Seward (1997). 
Table 2. HKF Equation of State Parameters Derived In This Study

\begin{tabular}{|c|c|c|c|c|c|c|c|c|c|c|c|}
\hline Species & $\Delta \mathbf{G}_{\mathrm{f}}^{\circ}$ & $\mathbf{S}^{o b}$ & $\mathrm{C}_{\mathrm{pr}}^{\text {ob }}$ & $V^{o c}$ & $a_{1}{ }^{d} \times 10$ & $a_{2}{ }^{a} \times 10^{-2}$ & $\mathbf{a}_{3}{ }^{\mathrm{e}}$ & $a_{4}{ }^{f} \times 10^{-4}$ & $\mathbf{c}_{1}{ }^{\mathrm{b}}$ & $\mathbf{c}_{2}{ }^{\mathrm{f}} \times 10^{-4}$ & $\omega^{\mathrm{a}} \times 10^{-5}$ \\
\hline $\mathbf{H}_{2} \mathbf{S}^{0 \mathrm{~g}}$ & -6673 & 30.0 & 42.27 & 34.81 & 6.4685 & 6.5969 & 6.1947 & -3.0517 & 32.3 & 4.1035 & -0.1774 \\
\hline $\mathbf{H S}^{-1}$ & 2860 & 16.3 & -23.90 & 20.65 & 5.1700 & 4.4743 & 4.0980 & -2.9750 & -1.9779 & -3.3952 & 1.63 \\
\hline $\operatorname{Au}(\mathbf{O H})^{0}$ & -27514 & 26.34 & -21.03 & 17.13 & 4.1575 & 2.3700 & 4.8319 & -2.8770 & -4.7748 & -7.3184 & 0.1432 \\
\hline $\mathbf{A u}(\mathbf{H S})^{0}$ & 8527 & 38.89 & 17.37 & 66.17 & 10.8066 & 18.6054 & -1.5302 & -3.5481 & 15.9948 & 0.5046 & -0.038 \\
\hline $\mathrm{Au}(\mathrm{HS})_{2}{ }^{-1}$ & 3820 & 49.0 & 28.93 & 83.0 & 13.4198 & 24.9861 & -4.0306 & -3.8119 & 31.2002 & 2.8580 & 0.8797 \\
\hline $\mathrm{H}_{3} \mathrm{AsO}_{3}{ }^{0}$ & -152910 & 48.9 & 49.57 & 49 & 8.4573 & 12.8691 & 0.7177 & -3.3110 & 34.8073 & 7.0632 & -0.038 \\
\hline $\mathrm{H}_{2} \mathrm{AsO}_{3}{ }^{-1}$ & -140289 & 31.0 & 45.1 & 47.6 & 8.5857 & 13.1826 & 0.5948 & -3.3240 & 41.3490 & 5.5208 & 0.82 \\
\hline $\mathrm{H}_{3} \mathrm{As}_{3} \mathrm{~S}_{6}{ }^{0}$ & -35728 & 99.0 & 105 & 93.97 & 14.6116 & 27.8963 & -5.1709 & -3.9322 & 67.1930 & 18.3539 & -0.038 \\
\hline $\mathrm{H}_{2} \mathrm{As}_{3} \mathrm{~S}_{6}^{-1}$ & -30844 & 96.7 & 112.75 & 91.99 & 14.4063 & 27.3951 & -4.9745 & -3.9115 & 73.5219 & 19.9324 & 0.1575 \\
\hline $\mathrm{HAs}_{3} \mathrm{~S}_{6}{ }^{-2}$ & -20057 & 82.66 & 89.58 & 80.06 & 13.3929 & 24.9204 & -4.0048 & -3.8092 & 76.8851 & 15.2133 & 1.9918 \\
\hline $\mathrm{Sb}(\mathrm{OH})_{3}{ }^{0}$ & -154010 & 49.43 & 39.09 & 54 & 9.1415 & 14.5397 & 0.0630 & -3.3801 & 28.6838 & 4.9284 & -0.038 \\
\hline $\mathrm{Sb}(\mathrm{OH})_{4}{ }^{-1}$ & -195038 & 42.28 & 22.96 & 44.58 & 8.1966 & 12.2325 & 0.9671 & -3.2847 & 28.6515 & 1.6426 & 0.9815 \\
\hline $\mathbf{H}_{2} \mathbf{S b}_{2} \mathbf{S}_{4}{ }^{0}$ & -35488 & 69.36 & 71.3 & 70.7 & 11.4268 & 20.1196 & -2.1236 & -3.6107 & 47.5025 & 11.4892 & -0.038 \\
\hline $\mathbf{H S b}_{2} \mathbf{S}_{4}{ }^{-1}$ & -28583 & 50.70 & 32.56 & 50.7 & 8.9913 & 14.1728 & 0.2068 & -3.3649 & 33.0864 & 3.5984 & 0.8540 \\
\hline $\mathbf{S b}_{2} \mathbf{S}_{4}^{-2}$ & -15622 & 42.38 & -30.48 & 44.66 & 8.7546 & 13.5948 & 0.4332 & -3.3410 & 12.3553 & -9.2424 & 2.6016 \\
\hline $\mathrm{Hg}(\mathrm{OH})_{2}{ }^{0}$ & -65575 & 38.9 & 17.4 & 66.3 & 10.8247 & 18.6495 & -1.5475 & -3.5500 & 16.0095 & 0.5098 & -0.038 \\
\hline $\mathrm{Hg}(\mathrm{HS})_{2}{ }^{0}$ & -9033 & 49.7 & 35.212 & 90.44 & 14.1279 & 26.7151 & -4.7081 & -3.8834 & 26.4159 & 4.1378 & -0.038 \\
\hline $\operatorname{HgS}(\mathrm{HS})^{-1}$ & -668 & 36.06 & 12.71 & 59.80 & 10.3118 & 17.3972 & -1.0567 & -3.4982 & 23.5270 & -0.4462 & 1.0756 \\
\hline $\mathrm{Hg}^{\mathbf{0}}$ & 8871 & -1.59 & 98.17 & 18.54 & 4.2842 & 2.6795 & 4.7106 & -2.8898 & 63.0565 & 16.9619 & -0.0536 \\
\hline $\operatorname{Ag}(\mathrm{OH})^{0}$ & -21782 & 11.27 & -28.2 & 3.87 & 2.2817 & -2.2100 & 6.6266 & -2.6876 & -10.6358 & -8.7796 & -0.038 \\
\hline $\operatorname{Ag}(\mathbf{H S}){ }^{0}$ & 963 & 23.6 & -7.85 & 28.7 & 5.6794 & 6.0863 & 3.3756 & -3.0306 & 1.2545 & -4.6343 & -0.038 \\
\hline $\operatorname{Ag}(\mathrm{HS})_{2}{ }^{-1}$ & -100 & 43.29 & 17.0 & 65 & 10.9860 & 19.0434 & -1.7018 & -3.5663 & 25.0312 & 0.4296 & 0.9662 \\
\hline
\end{tabular}

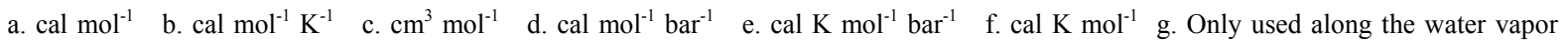
saturation curve, otherwise Plyasunov et al. (2000) used h. Calculated from the temperature dependence of $\log \mathrm{K}$ for reaction (30) using the standard entropy of the elements taken from Wagman, et al. (1982) i. Barbero et al. (1982) j. Shock et al. (1989) k. Tanger and Helgeson (1988) 1. Akinfiev et al. (1992) 
A

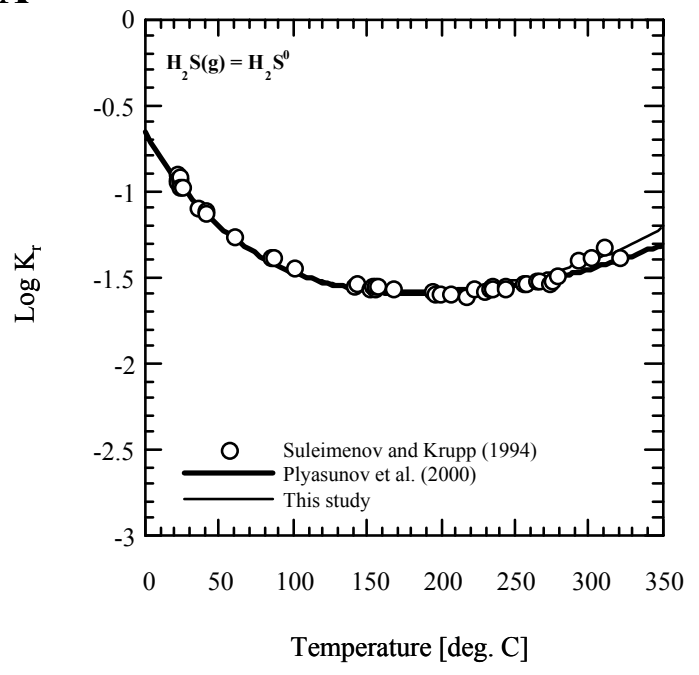

C

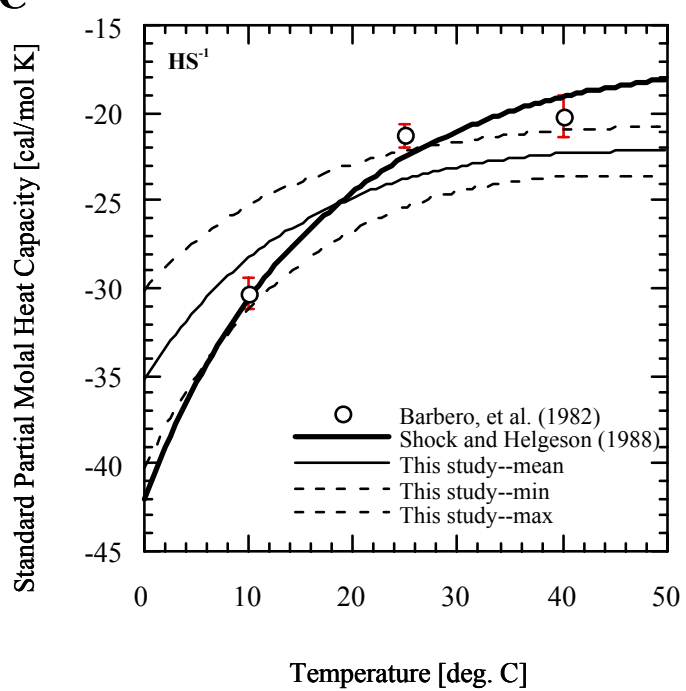

B

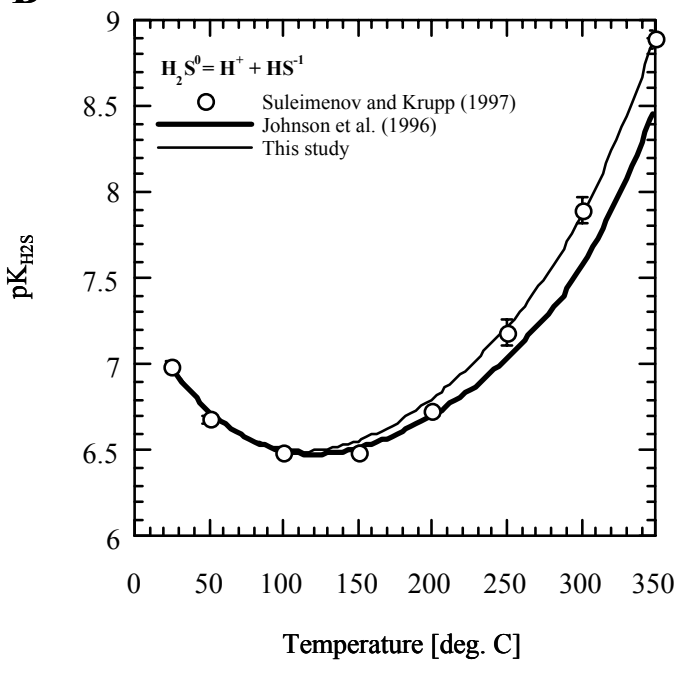

D

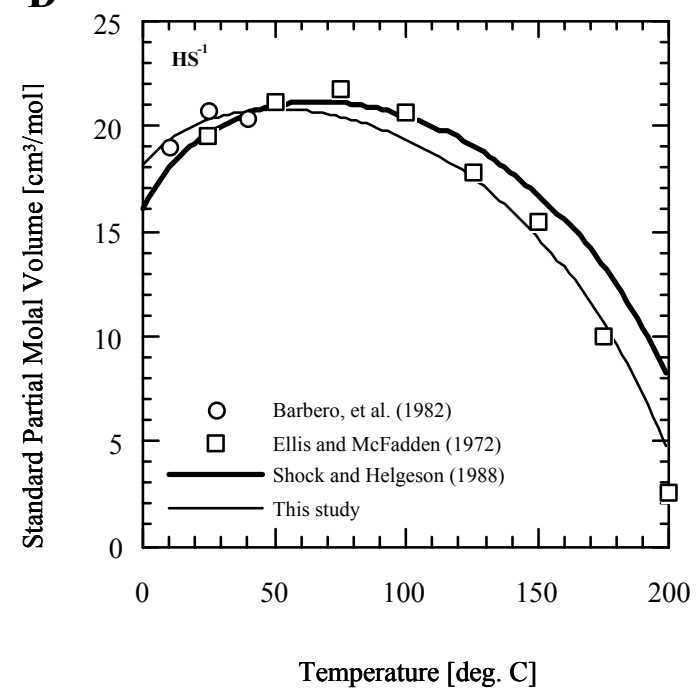

Fig. 1. Comparison between experimental data (symbols), predictions (solid lines), and calculated uncertainties (dashed lines) for aqueous sulfide species: A) Equilibrium constants for reaction (18); B) Standard partial molal heat capacities for $\mathrm{H}_{2} \mathrm{~S}^{0}$; C) Standard partial molal volumes for $\mathrm{H}_{2} \mathrm{~S}^{0}$; D) Equilibrium constants for reaction (19). 
To remove this inconsistency, the HKF equation of state parameters for $\mathrm{HS}^{-1}$ were revised in this study to include the latter data in the regression calculations. First, $\left[c_{2}\right]$ and $[\omega]$ were modified from their original values. Because the correlation between $\left[\bar{S}^{o}\right]$ and $[\omega]$ (Eq. 17) is integral to the framework of the HKF equation of state, the maximum deviation in $[\omega]$ from the correlation was restricted by the deviation of the $\mathrm{La}^{3+}$ species from the $\left[\bar{S}^{o}\right]-[\omega]$ correlation for trivalent cations, which was considered by Shock et al. (1988) to still be within the margin of error of the HKF equation of state. After making this assumption, an initial value of $\left[c_{2}\right]$ was obtained from regression against the new equilibrium constant data using the updated $[\omega]$ value and the HKF equation of state parameters of Shock et al. (1988). $\left[a_{1}\right]$ through $\left[a_{4}\right]$ were subsequently obtained from volumetric data, $\left[c_{1}\right]$ from the heat capacity data, and all parameters except $[\omega]$ updated by iteration until convergence was obtained.

Table 2 reports the revised HKF equation of state parameters, and Figure 1B through 1D show the new predictions for the equilibrium constant, standard partial molal heat capacity, and standard partial molal volume, respectively. Although prediction of the equilibrium constant and standard partial molal volume are improved over the predictions of Shock and Helgeson (1988), predictions for the standard partial molal heat capacity are worse, emphasizing a fundamental incompatibility between the measurements of Barbero et al. (1982), Suleimenov and Seward (1997), and the HKF equation of state model for ions (Tanger and Helgeson, 1988).

Although the experimental techniques of Barbero et al. (1982) are relatively standard, Suleimenov and Seward (1997) admitted great difficulty in dealing with their dilute $\mathrm{H}_{2} \mathrm{~S}^{0}$ solutions, with any hydrogen sulfide loss due to volatility or corrosion leading to erroneous results. Similarly, recent molecular dynamics studies of Driesner et al. (1998) suggest that the HKF correction for dielectric saturation and solvent compressibility may be species dependent, resulting in an underestimated solvation contribution to $\left[\Delta \bar{G}^{o}\right]$ when the universal g-correction factor described 
above is applied to $\mathrm{HS}^{-1}$. This latter possibility is particularly intriguing because it implies that the HKF equation of state is only predictive at the highest temperatures for species whose equation of state parameters are derived from high temperature heat capacity or $\log \mathrm{K}_{\mathrm{r}}$ data. Moreover, those ionic species whose parameters are derived from $\log \mathrm{K}_{\mathrm{r}}$ data and various $\mathrm{HKF}$ equation of state correlations necessarily produce fictive values for $\left[\bar{C}_{\mathrm{Pr}}^{o}\right]$ because the error associated with applying a universal g-function correction is incorporated into the $\left[c_{1}\right]$ and $\left[c_{2}\right]$ heat capacity parameters.

Based on the close match between Suleimenov and Seward (1997) and other studies where experimental data are available, it was decided in this investigation to accept the HKF equation of state derived using the method outlined above, pending future investigations clarifying this issue.

\section{Aqueous Gold Complexes}

$\mathrm{Au}(\mathrm{OH})^{0}$

The HKF equation of state parameters for $\mathrm{Au}(\mathrm{OH})^{0}$ were derived from the solubility study of Zotov et al. (1985). Because the high pressure experiments which used different oxidation buffers produced inconsistent equilibrium constants for the reaction:

$$
\mathrm{Au}(\mathrm{s})+0.5 \mathrm{H}_{2} \mathrm{O}+0.25 \mathrm{O}_{2}(\mathrm{~g})=\mathrm{Au}(\mathrm{OH})^{0}
$$

only the experiments performed at 500 bars and temperatures from 300 to $500^{\circ} \mathrm{C}$ were included in the regression calculations. $\left[\Delta \bar{G}_{f}^{o}\right]$ and $[\omega]$ were selected as the regression parameters, and $\left[\bar{S}^{o}\right],\left[\bar{C}_{\mathrm{Pr}}^{o}\right]$, and $\left[\bar{V}^{o}\right]$ were obtained from the correlations for the first hydroxylation of a monovalent cation (Shock et al., 1997).

The parameters reported in Table 2 are consistent with correlation between the standard partial molal heat capacity and entropy for nonmetal hydrogen-bearing acids and oxyanions (Shock et al., 1997) (Fig. 2A). They are also consistent with the correlation developed in this study between the 
A

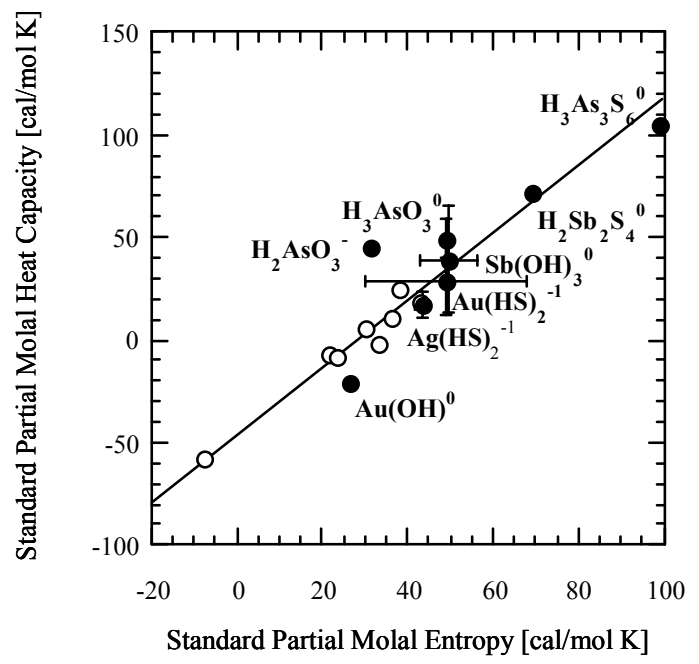

C

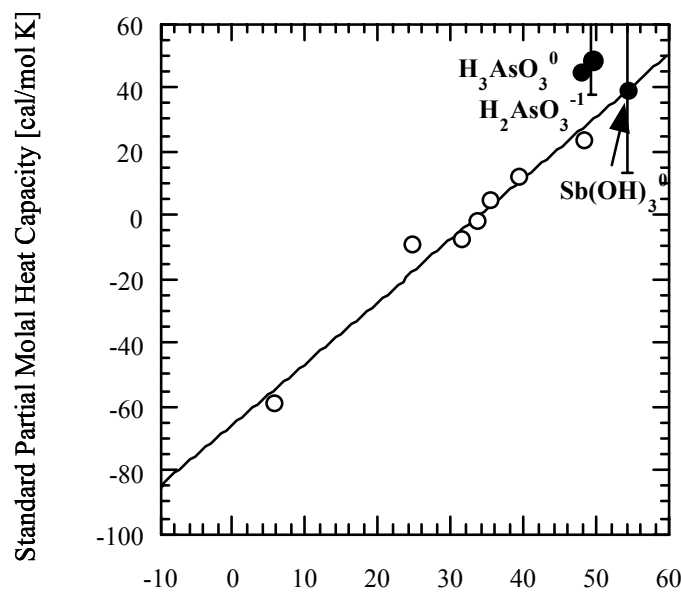

Standard Partial Molal Entropy [cal/mol K]
B

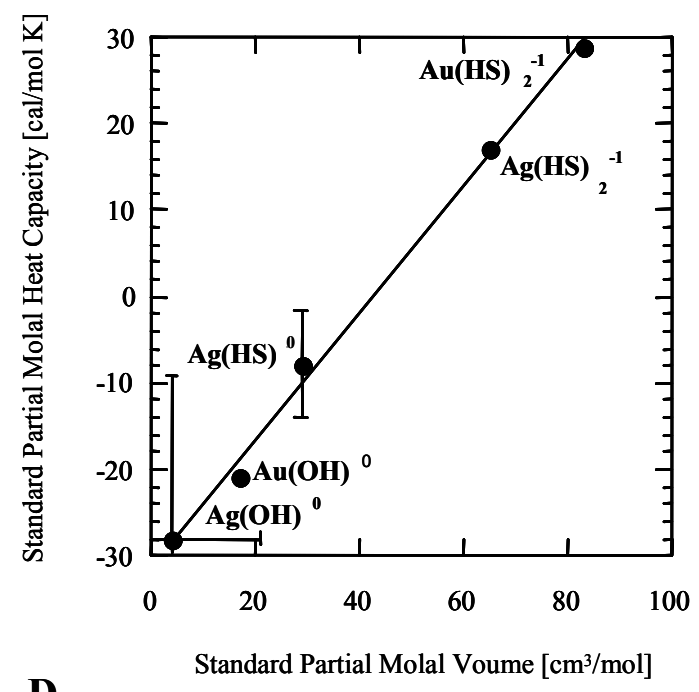

D

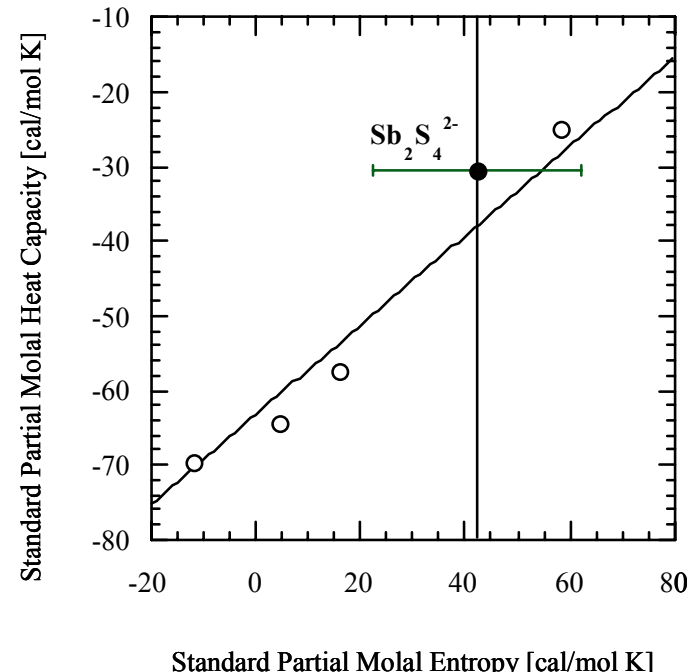

Fig. 2. Correlations (solid lines), predicted standard partial molal thermodynamic properties from this study (closed circles), and standard partial molal thermodynamic properties from previous studies (open circles): A) Correlations between standard partial molal heat capacities and entropies for hydrogen-bearing nonmetal acids and oxyanions (Eq. 21) (Shock et al, 1997);

B) Correlations between standard partial molal heat capacities and volumes for metal complexes derived in this study (Eq. 22); C) Correlations between standard partial molal heat capacities and volumes for hydrogen-bearing nonmetal acids and oxyanions (Eq. 29) (Shock et al, 1997); D) Correlations between standard partial molal heat capacities and entropies for divalent oxyanions (Shock et al, 1997). 
standard partial molal heat capacity and volume for metal complexes (Fig. 2B). The equations for these linear correlations are:

$$
\begin{aligned}
& \bar{C}_{\mathrm{Pr}}^{o}=1.65 \bar{S}^{o}-46.8 ; \text { and } \\
& \bar{C}_{\mathrm{Pr}}^{o}=0.73 \bar{V}^{o}-31.16 ;
\end{aligned}
$$

respectively. Predicted equilibrium constants for reaction (20) are shown on Figure 3A.

$A u(H S)^{0}$

Solubility constants for the following reaction:

$$
\mathrm{Au}(\mathrm{s})+\mathrm{H}_{2} \mathrm{~S}^{0}=\mathrm{AuHS}^{0}+0.5 \mathrm{H}_{2}(\mathrm{~g})
$$

have most recently been calculated by Renders and Seward (1989), Hayashi and Ohmoto (1991), Benning and Seward (1996), Gibert et al. (1998), Dadze et al. (2000), and Stefansson and Seward (2000). Gibert et al. (1998) recalculated the experiments of Hayashi and Ohmoto (1991) and Benning and Seward (1996) in terms of the thermodynamic properties of $\mathrm{H}_{2} \mathrm{~S}^{0}$ and $\mathrm{HS}^{-1}$ available from the existing SUPCRT database, and found their own solubilities were consistent with those of Hayashi and Ohmoto (1991), but differed by up to 3 orders of magnitude from those of Benning and Seward (1996). Because Gibert et al. (1998) also found that the solubilities of Benning and Seward (1996) were $\mathrm{pH}$ dependent even below a $\mathrm{pH}$ of 4.0 , it is likely that the charged species $\mathrm{Au}(\mathrm{HS})_{2}{ }^{-1}$ controlled solubility in the latter experiments. Consequently, the data of Benning and Seward (1996) and Stefansson and Seward (2000) (which are consistent with the former) were omitted from regression calculations.

In interpreting the recalculated solubility experiments of Hayashi and Ohmoto (1991), the assumption was made that their dominant species was $\mathrm{Au}(\mathrm{HS})^{0}$ rather than $\mathrm{HAu}(\mathrm{HS})_{2}{ }^{0}$. Evidence for $\mathrm{Au}(\mathrm{HS})^{0}$ is provided by Renders and Seward $(1989)$ at $25^{\circ} \mathrm{C}$, who plotted $\log \mathrm{m}_{\mathrm{Au}, \mathrm{T}}$ versus $\log \mathrm{m}_{\mathrm{S}, \mathrm{T}}$ and obtained a slope of $+0.5\left(\mathrm{HAu}(\mathrm{HS})_{2}{ }^{0}\right.$ should produce a slope of +1.5$)$. Also, the molecular orbital calculations of Tossell (1996) demonstrate that $\mathrm{Au}(\mathrm{HS})^{0}$ is thermodynamically more stable than 
A

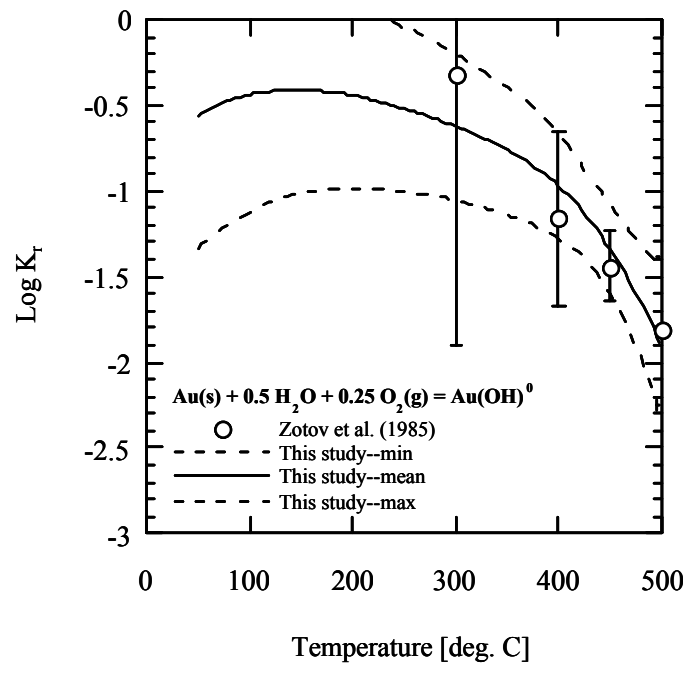

C

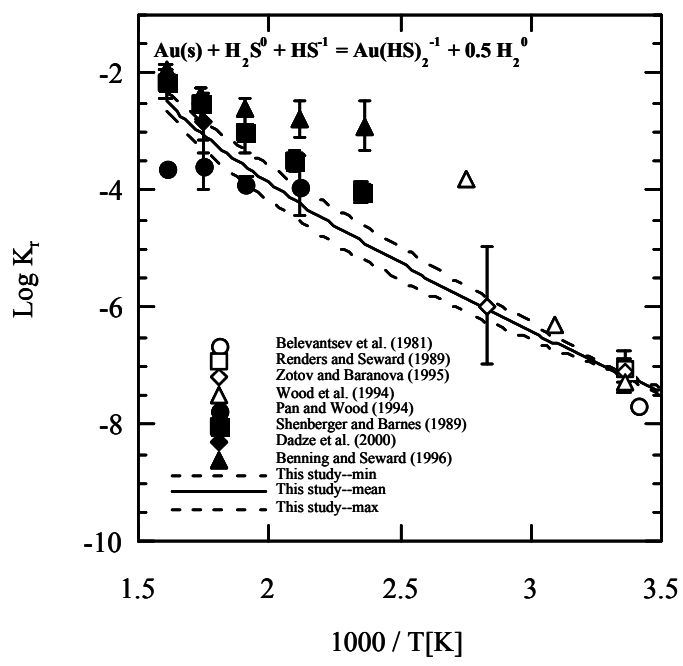

B

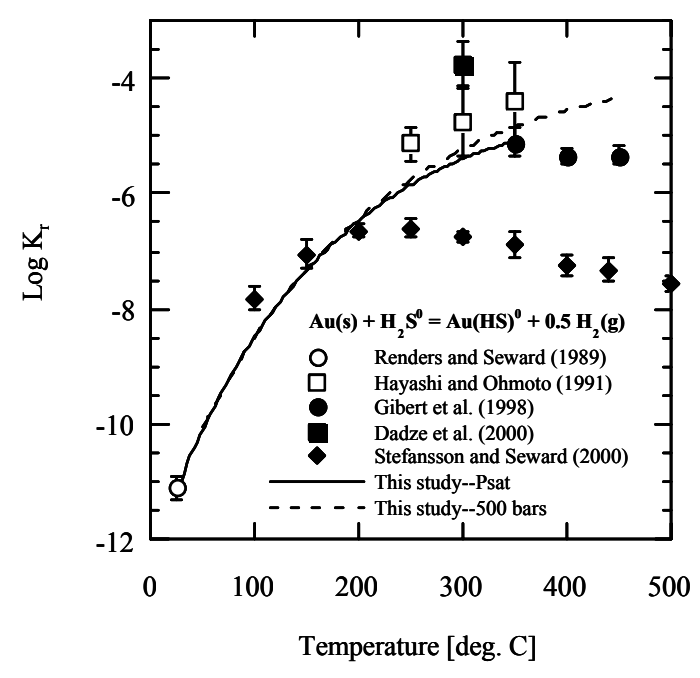

D

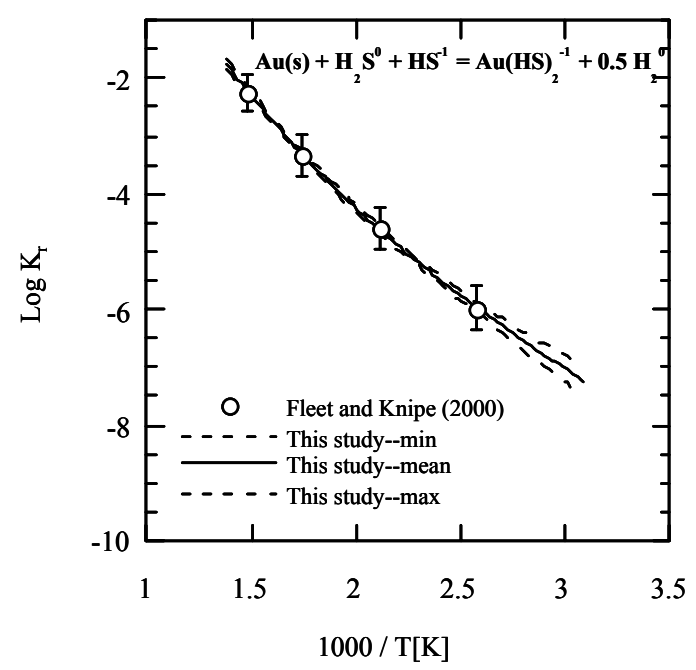

Fig. 3. Comparison between experimental data (symbols), predictions (solid lines), and calculated uncertainties (dashed lines) for aqueous gold complexes: A) Equilibrium constants for reaction (20); B) Equilibrium constants for reaction (23) (data by Stefansson and Seward (2000) were not included in regression calculations); C) Equilibrium constants for reaction (23) written as $1000 / \mathrm{T}[\mathrm{K}]$ at $\mathrm{P}_{\text {sat }}$; D) Equilibrium constants for reaction (23) written as $1000 / \mathrm{T}[\mathrm{K}]$ at 1500 bars. 
$\mathrm{HAu}(\mathrm{HS})_{2}{ }^{0}$. Finally, Gibert et al. (1998) suggested that interpretations of Hayashi and Ohmoto (1989) are tainted by the uncertainty of measuring the volume of silica tubes and large experimental scatter.

Before regression calculations were performed, the contribution of $\mathrm{Au}(\mathrm{HS})_{2}{ }^{-1}$ (based on the HKF equation of state parameters described below) was subtracted from the experimentally observed concentration (assuming an activity coefficient for the complex equal to $\gamma_{\mathrm{HS}-1}$ ). This contribution was

never greater than $3.5 \%$. $\left[\Delta \bar{G}_{f}^{o}\right]$ was then calculated from the solubility measurements of Renders and Seward (1989) at $25^{\circ} \mathrm{C}$ from the equilibrium constant for:

$$
\mathrm{Au}(\mathrm{s})+\mathrm{H}_{2} \mathrm{~S}^{0}=\mathrm{AuHS}^{0}+0.5 \mathrm{H}_{2}(\mathrm{~g})
$$

$\left[\bar{S}^{o}\right]$ was obtained from regression of high temperature experimental data, $\left[\bar{C}_{\mathrm{Pr}}^{o}\right]$ from the correlation for the hydroxylation of monovalent cations (Shock et al., 1997), $\left[\bar{V}^{o}\right]$ from equation (22), and [ $\left.\omega\right]$ from Sverjensky et al. (1997) for neutral aqueous species.

Table 2 reports the equation of state parameters for this species. The predicted equilibrium constants for reaction (24) are shown on Figure 3B.

$\mathrm{Au}(\mathrm{HS})_{2}^{-1}$

The solubility of gold at $25^{\circ} \mathrm{C}$ in neutral to mildly alkaline solutions has been investigated by Renders and Seward (1989), Wood et al. (1994), and Zotov and Baranova (1995). Renders and Seward (1989) and Zotov and Baranova (1995) both performed experiments on the solid phase $\mathrm{Au}_{2} \mathrm{~S}(\mathrm{~s})$ and calculated equilibrium constants for the reaction:

$$
0.5 \mathrm{Au}_{2} \mathrm{~S}(\mathrm{~s})+1.5 \mathrm{H}_{2} \mathrm{~S}^{0}=\mathrm{Au}(\mathrm{HS})_{2}^{-1}+\mathrm{H}^{+} \text {. }
$$

In order to compare the results of these two studies to high temperature experiments, it was first necessary in this study to recalculate Au solubility in terms of the reaction:

$$
\mathrm{Au}(\mathrm{s})+\mathrm{H}_{2} \mathrm{~S}^{0}+\mathrm{HS}^{-1}=\mathrm{Au}(\mathrm{HS})_{2}^{-1}+0.5 \mathrm{H}_{2}{ }^{0} .
$$

Because this necessitated a knowledge of $\left[\Delta \bar{G}_{f}^{o}\right]$ for the solid phase in reaction (25), a choice also had to be made between the thermodynamic information for $\mathrm{Au}_{2} \mathrm{~S}(\mathrm{~s})$ provided by the stability product 
of De Cugnac-Pailliotet and Pouradier (1972) and the high temperature solid solution model of Barton (1980). Because the latter exhibited considerable scatter in the data and also consisted of an extrapolation from $170^{\circ} \mathrm{C}$ to $25^{\circ} \mathrm{C}$, it was deemed less reliable and excluded from this study.

A comparison of the different re-speciated experimental studies is shown on Figure 3C. Although the solubility constants for reaction (26) are relatively similar at $25^{\circ} \mathrm{C}$, differences at $350^{\circ} \mathrm{C}$ span nearly two orders of magnitude. These differences have been explained by Akinfiev and Zotov (2001) as being caused by not holding $\mathrm{P}_{\mathrm{H} 2 \mathrm{~S}}$ constant in some experiments. Also, Gibert et al. (1998) proposed that the most reliable experimental results at elevated temperatures are those of Shenberger and Barnes (1989), because reaction (26) should be isocoulombic (i.e. $\Delta C_{P, R}^{o}=0, \Delta H_{R}^{o}$ constant, and a plot of $\log \mathrm{K}$ vs. $1 / \mathrm{T}$ a straight line). Although the high temperature data of Shenberger and Barnes (1989) are consistent with the low temperature data in this regard, Fleet and Knipe (2000) suggested the experiments of Shenberger and Barnes (1989) contain systematic sampling errors.

In this study, $\left[\Delta \bar{G}_{f}^{o}\right]$ for $\mathrm{Au}(\mathrm{HS})_{2}{ }^{-1}$ was constrained by the mean value of the three equilibrium constants at $25^{\circ} \mathrm{C} .\left[\bar{S}^{o}\right],\left[\bar{C}_{\mathrm{Pr}}^{o}\right]$, and $\left[\bar{V}^{o}\right]$ were then calculated from regression on the experimental data of Fleet and Knipe (2000), and [ $\omega]$ from correlation (17). Predicted values of $\left[\bar{V}^{o}\right]$ are consistent with the experiments of Zotov and Baranova (1995), and $\left[\bar{S}^{o}\right],\left[\bar{C}_{\mathrm{Pr}}^{o}\right]$, and $\left[\bar{V}^{o}\right]$ with the correlations on Figures $2 \mathrm{~A}$ and $2 \mathrm{~B}$. The $\log \mathrm{K}_{\mathrm{r}}$ values are nearly isocoulombic along the water vapor saturation curve (Fig. 3C), and at 1500 bars (Fig. 3D).

\section{Aqueous Arsenic Complexes}

$\mathrm{H}_{3} \mathrm{AsO}_{3}{ }^{0}$

The HKF equation of state parameters for this species were previously derived by Pokrovski et al. (1996). Their parameters were re-derived in this study in order to obtain an error envelope for reaction (27) below. [ $\Delta \bar{G}_{f}^{o}$ ] was obtained from the following two reactions: 


$$
\begin{aligned}
& 0.5 \mathrm{As}_{2} \mathrm{~S}_{3}(\mathrm{~s})+3 \mathrm{H}_{2} \mathrm{O}=\mathrm{H}_{3} \mathrm{AsO}_{3}{ }^{0}+1.5 \mathrm{H}_{2} \mathrm{~S}^{0} \\
& \mathrm{As}_{2} \mathrm{O}_{3}(\mathrm{~s})+3 \mathrm{H}_{2} \mathrm{O}=2 \mathrm{H}_{3} \mathrm{AsO}_{3}{ }^{0}
\end{aligned}
$$

using the mean value of $\left[\Delta \bar{G}_{f}^{o}\right]$ from the equilibrium constant of Mironova et al. (1984) (Eq. (27)), Webster (1990) (Eq. (27)) and Baes and Mesmer (1976) (Eq. (28)), and also by invoking the thermodynamic properties for the solid phases tabulated in Table 4 of Pokrovski et al. (1996) (Table 1 of this study). [ $\left.\bar{S}^{o}\right]$ was calculated using the temperature dependence of the equilibrium constant of reaction (28), the entropy of arsenolite (Table 1), and the entropy of $\mathrm{H}_{2} \mathrm{O}$ (Johnson et al., 1992). [ $\left.\bar{C}_{\mathrm{Pr}}^{o}\right]$ was determined from regression of the experimental data of arsenolite and claudetite to $90^{\circ} \mathrm{C}$ (Anderson and Story, 1923; Linke, 1958; Stranski et al., 1958; Baes and Mesmer, 1976; Pokrovski et al., 1996), and orpiment to $300^{\circ} \mathrm{C}$ (Stranski et al., 1958; Mironova et al., 1984; Webster, 1990; Pokrovski et al., 1996). [ $\left.\bar{V}^{o}\right]$ was calculated from the density measurements of $\mathrm{As}_{2} \mathrm{O}_{3}-\mathrm{H}_{2} \mathrm{O}$ solutions (Anderson and Story, 1923). Finally, [ $\omega]$ was obtained from Sverjensky et al. (1997) for neutral aqueous species.

Table 2 reports the resulting HKF equation of state parameters for this species, and Figures $2 \mathrm{~A}$ and $2 \mathrm{C}$ show that the parameters are consistent with equation (21) and the following equation for nonmetal hydrogen-bearing acids and oxyanions (Shock et al., 1997):

$$
\bar{C}_{\mathrm{Pr}}^{o}=1.94 \bar{V}^{o}-65.8 .
$$

Solubility is predicted well, as illustrated on Fig. 4A.

$\mathrm{H}_{2} \mathrm{AsO}_{3}^{-1}$

Recent experimental data of Zakaznova et al. (2000) suggests that the HKF equation of state parameters of this species originally derived by Shock and Helgeson (1988) do not accurately predict the equilibrium constant of the following reaction:

$$
\mathrm{H}_{3} \mathrm{AsO}_{3}{ }^{0}=\mathrm{H}^{+}+\mathrm{H}_{2} \mathrm{AsO}_{3}{ }^{-1}
$$


$\mathbf{A}$

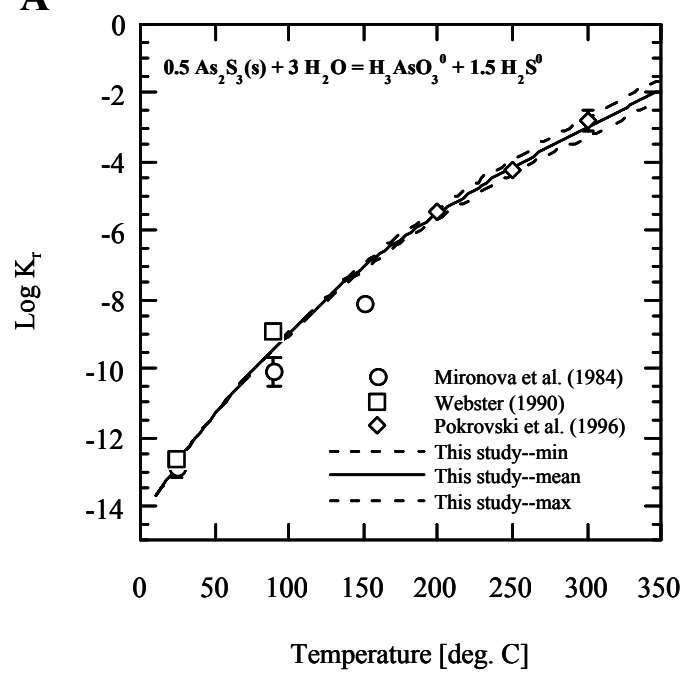

C

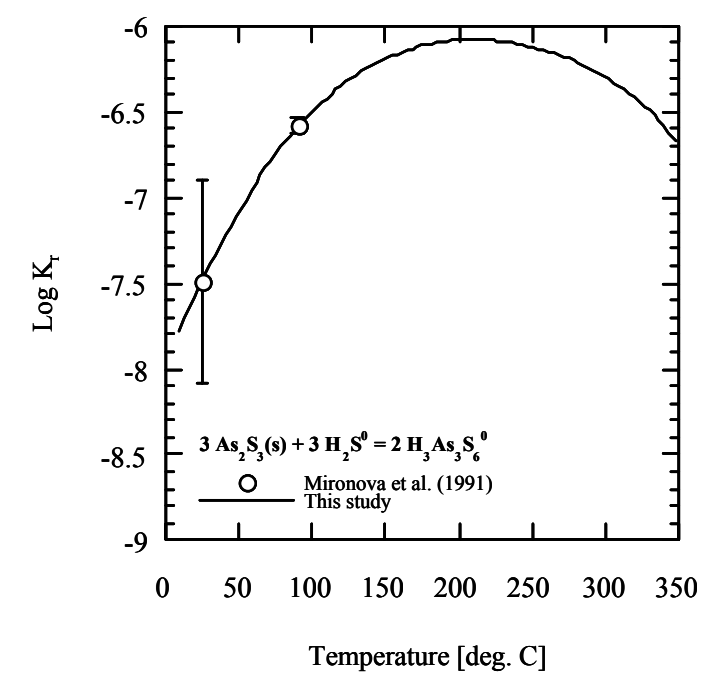

B

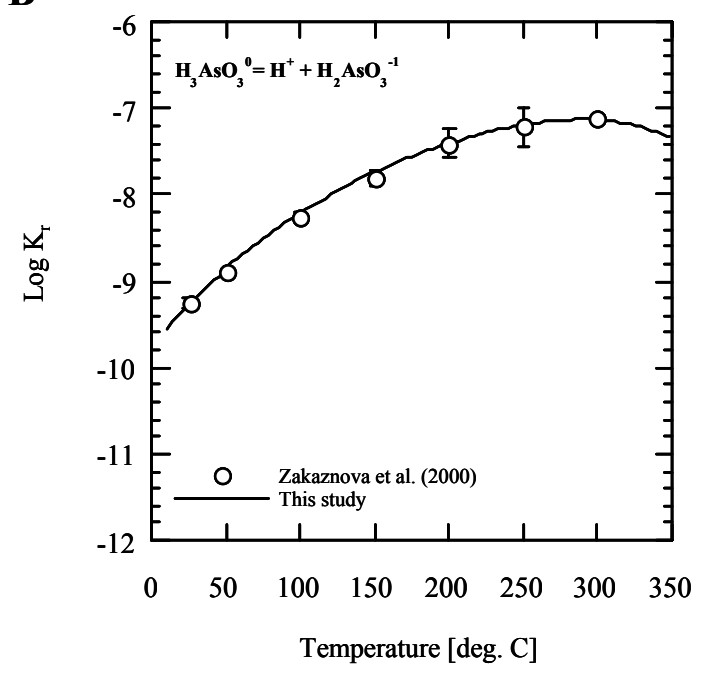

D

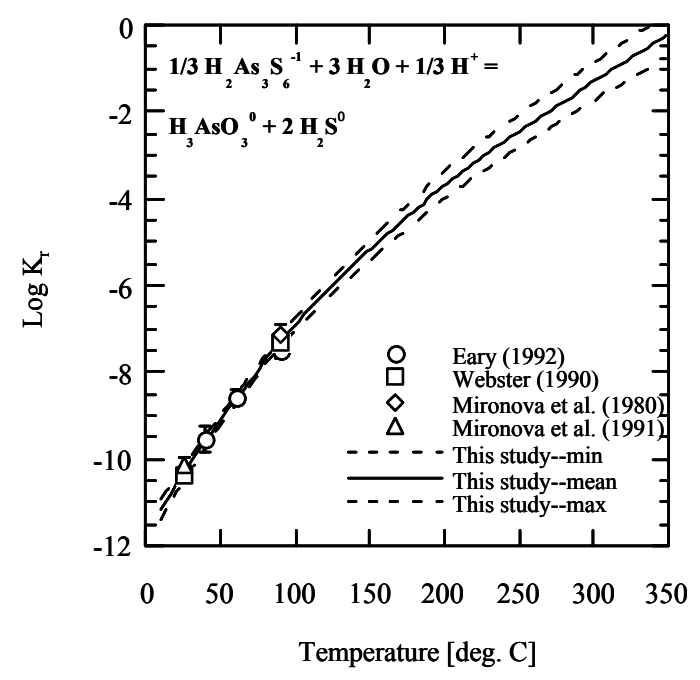

Fig. 4. Comparison between experimental data (symbols), predictions (solid lines), and calculated uncertainties (dashed lines) for aqueous arsenic complexes: A) Equilibrium constants for reaction (27); B) Equilibrium constants for reaction (30); C) Equilibrium constants for reaction (31); D) Equilibrium constants for reaction (32). 


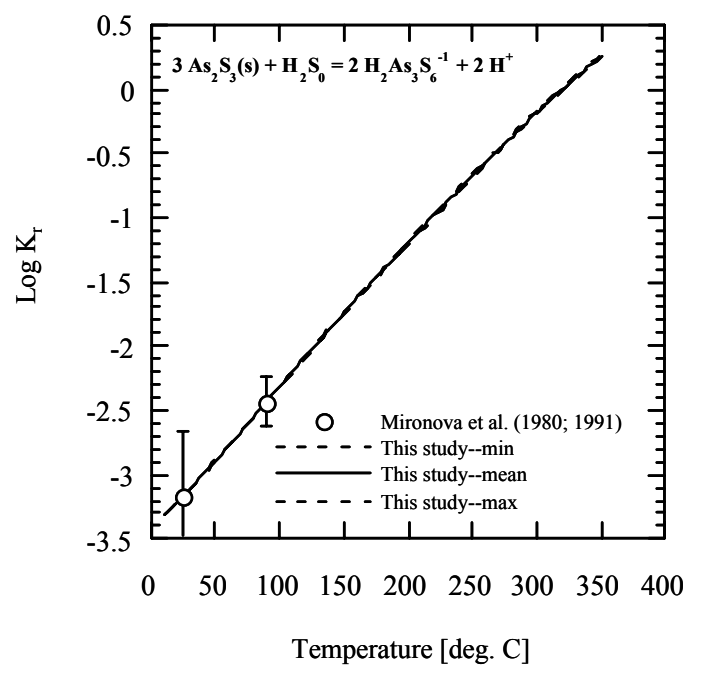

Fig. 4.E) Comparison between experimental data (symbols), predictions (solid lines), and calculated uncertainties (dashed lines) for $\mathrm{HAs}_{3} \mathrm{~S}_{6}{ }^{-2}$ 
(Fig. 4B). Parameters were re-derived in this study using values of $\left[\Delta \bar{G}_{f}^{o}\right]$ and $\left[\bar{S}^{o}\right]$ obtained from Wagman et al. (1982) as initial estimates. The latter parameter was then adjusted, along with $\left[\bar{C}_{\mathrm{Pr}}^{o}\right]$, $\left[\bar{V}^{o}\right]$, and $[\omega]$ to graphically minimize error between predicted thermodynamic properties, the correlations of equations (21), (29) and (17), respectively, and the equilibrium constant for reaction (30). Table 2 reports the values updated in this study. Predictions relative to reaction (30) are displayed on Figure 4B.

$H_{3} A s_{3} S_{6}{ }^{0}$

The occurrence of this species has been the subject of considerable debate. Mironova and Zotov (1980) originally reported the presence of a neutral sulfide complex of the form $\mathrm{H}_{2} \mathrm{As}_{2} \mathrm{~S}_{4}{ }^{0}$ in their experiments at $90^{\circ} \mathrm{C}$ and $\mathrm{pH}$ of 1.19 . Spycher and Reed (1989) re-interpreted these data to be $\mathrm{H}_{3} \mathrm{As}_{3} \mathrm{~S}_{6}{ }^{0}$ based on their calculations that demonstrated trimers are favored over dimers. Mironova et al. (1991) later revised their earlier hypothesis based on the fact that the solubility of As was not found to change with total reduced sulfide concentration at $25^{\circ} \mathrm{C}$ and $90^{\circ} \mathrm{C}$ in acidic solutions as would be predicted from the following reaction:

$$
3 \mathrm{As}_{2} \mathrm{~S}_{3}(\mathrm{~s})+3 \mathrm{H}_{2} \mathrm{~S}^{0}=2 \mathrm{H}_{3} \mathrm{As}_{3} \mathrm{~S}_{6}{ }^{0} \text {. }
$$

They instead proposed that the species $\mathrm{As}_{2} \mathrm{~S}_{3} \bullet \mathrm{H}_{2} \mathrm{O}$ is important in acidic, sulfide solutions. Finally, Helz et al. (1995) suggested the experiments of Mironova et al. (1991) with the highest $\mathrm{m}_{\mathrm{H} 2 \mathrm{~S}}$ suffered from experimental contamination or colloid formation because if $\mathrm{As}_{2} \mathrm{~S}_{3} \bullet \mathrm{H}_{2} \mathrm{O}$ were an important species then the solubility of amorphous orpiment would have been significantly greater than that reported by Eary (1992).

Not enough information is available to resolve this issue. Because evidence exists for the species $\mathrm{H}_{2} \mathrm{As}_{3} \mathrm{~S}_{6}{ }^{-1}$ and $\mathrm{HAs}_{3} \mathrm{~S}_{6}^{-2}$, and because Helz et al. (1995) used ab initio quantum mechanical predictions and spectroscopic data to confirm the stability of As-S trimers relative to the dimers, it was assumed in this study that $\mathrm{H}_{3} \mathrm{As}_{3} \mathrm{~S}_{6}{ }^{0}$ also exists. To reconcile this tentative assumption with the 
results of Mironova et al. (1991), only those data points that conformed to a predicted slope of +1.5 on a plot of $\log \mathrm{m}_{\mathrm{H} 2 \mathrm{~S}}$ versus $\log \mathrm{m}_{\mathrm{As}}$ were included in regression calculations. Despite the assertions of Mironova et al. (1991) that a sulfide complex was present in their experiments at $150^{\circ} \mathrm{C}$, no evidence of a sulfide species was found at this temperature after the contribution due to $\mathrm{H}_{3} \mathrm{AsO}_{3}{ }^{0}$ was subtracted. Consequently, regression calculations were limited to the $\log \mathrm{K}_{\mathrm{r}}$ data for reaction (31) at 25 and $90^{\circ} \mathrm{C}$.

Figure $4 \mathrm{C}$ shows the resulting predictions for the case where $\left[\Delta \bar{G}_{f}^{o}\right]$ was calculated from the equilibrium constant, $\left[\bar{S}^{o}\right]$ was regressed, $\left[\bar{C}_{\mathrm{Pr}}^{o}\right]$ obtained by assuming reaction (31) is isocoulombic, $\left[\bar{V}^{o}\right]$ calculated from equation (29), and $[\omega]$ taken from Sverjensky et al. (1997). Although the methodology adopted for this species is consistent with equation (21) (Fig. 2A), more experimental data are required.

$\mathrm{H}_{2} \mathrm{As}_{3} \mathrm{~S}_{6}^{-1}$

Many different investigators have obtained data suggesting arsenic is soluble as the complex $\mathrm{H}_{2} \mathrm{As}_{3} \mathrm{~S}_{6}{ }^{-1}$. Figure 4D shows these various studies written in terms of aqueous species so that the solubility study of Eary (1992) (which measured the solubility of amorphous orpiment) could be included. The reaction shown on the figure is:

$$
1 / 3 \mathrm{H}_{2} \mathrm{As}_{3} \mathrm{~S}_{6}{ }^{-1}+3 \mathrm{H}_{2} \mathrm{O}+1 / 3 \mathrm{H}^{+}=\mathrm{H}_{3} \mathrm{AsO}_{3}{ }^{0}+2 \mathrm{H}_{2} \mathrm{~S}^{0}
$$

which was calculated for the studies of Mironova and Zotov (1980), Mironova et al. (1991), and Webster (1992) from the equilibrium constant for the reaction:

$$
3 / 2 \mathrm{As}_{2} \mathrm{~S}_{3}(\mathrm{~s})+3 / 2 \mathrm{H}_{2} \mathrm{~S}=\mathrm{H}_{2} \mathrm{As}_{3} \mathrm{~S}_{6}{ }^{-1}+\mathrm{H}^{+},
$$

and from the $\left[\Delta \bar{G}^{o}\right]$ of $\mathrm{H}_{3} \mathrm{AsO}_{3}{ }^{0}$ obtained in this study. Eary (1992) directly measured the solubility of both $\mathrm{H}_{3} \mathrm{AsO}_{3}{ }^{0}$ and $\mathrm{H}_{2} \mathrm{As}_{3} \mathrm{~S}_{6}{ }^{-1}$ in equilibrium with amorphous orpiment and subsequently subtracted out the solid phase, so no recalculation was required. 
In order to derive the thermodynamic data for this species, it was first necessary to correct the $90^{\circ} \mathrm{C}$ data of Webster (1992) and Mironova et al. (1980 and 1991) for the dissociation constant of

$\mathrm{H}_{2} \mathrm{~S}^{0}$. Once the aqueous speciation was known for each set of experiments, $\left[\Delta \bar{G}_{f}^{o}\right]$ and $\left[\bar{S}^{o}\right]$ were calculated from regression, and $\left[\bar{C}_{\mathrm{Pr}}^{o}\right],\left[\bar{V}^{o}\right]$, and $[\omega]$ from equations (21), (29) and (17), respectively. Results are displayed on Figure 4D.

$H A s_{3} S_{6}^{-2}$

The data of Mironova et al. (1980 and 1991) were analyzed to derive the HKF equation of state parameters for $\mathrm{HAs}_{3} \mathrm{~S}_{6}{ }^{-2}$. Because Mironova et al. (1980 and 1991) attributed solubility to a dimer species, their experiments were re-speciated and the HKF parameters derived analogous to those for $\mathrm{H}_{2} \mathrm{As}_{3} \mathrm{~S}_{6}{ }^{-1}$. Figure 4E displays the resulting predictions.

\section{Aqueous Antimony Complexes}

\section{$\mathrm{Sb}(\mathrm{OH})_{3}{ }^{0}$}

The HKF equation of state parameters for $\mathrm{Sb}(\mathrm{OH})_{3}{ }^{0}$ have most recently been calculated by Zotov et al. (2003). Differences in predicted and measured $\left[\Delta \bar{G}_{i}^{o}\right]$ for $\mathrm{Sb}(\mathrm{OH})_{3}{ }^{0}$ from valentite, senarmontite, stibnite, and native antimony solubility experiments are generally within $0.2 \log$ units for most data; however, their predictions systematically deviate from the stibnite solubility experiments of Krupp (1988) at elevated temperatures. This deviation is caused by minimizing the least squares error with respect to the high temperature antimony solubility experiments of Shikina and Zotov (1991).

Considering the possibility that the HKF equation of state does not accurately characterize electrostatic interactions at elevated temperatures (see the discussion under $\mathrm{HS}^{-1}$ above), regression calculations in this study excluded the solubility of $\mathrm{Sb}(\mathrm{cr})$ in an $\mathrm{H}_{2}$ atmosphere at $450^{\circ} \mathrm{C}$ (Shikina and 
Zotov, 1991). The experimental results of Krupp (1988) and Shikina and Zotov (1999) were then respeciated and the former reinterpreted (Krupp, 1988 proposed the species $\mathrm{Sb}_{2} \mathrm{~S}_{2}(\mathrm{OH})_{2}{ }^{0}$ rather than $\left.\mathrm{Sb}(\mathrm{OH})_{3}{ }^{0}\right)$. After subtracting the contribution due to the sulfide complex $\mathrm{H}_{2} \mathrm{Sb}_{2} \mathrm{~S}_{4}{ }^{0}$ from the total antimony concentration of the experiments, $\left[\Delta \bar{G}^{o}\right]$ was included in regression calculations. $\left[\Delta G_{f}^{o}\right]$ was fixed by the solubility of senarmontite at $25^{\circ} \mathrm{C}$ (Popova et al., 1975), $\left[\bar{S}^{o}\right]$ and $\left[\Delta C_{P}^{o}\right]$ determined from regression, $\left[\bar{V}^{o}\right]$ obtained from Zotov et al. (2003), and $[\omega]$ from Sverjensky et al. (1997) for neutral aqueous species.

Table 2 reports the HKF equation of state parameters for $\mathrm{Sb}(\mathrm{OH})_{3}{ }^{0}$ and Figures $2 \mathrm{~A}$ and $2 \mathrm{C}$ show how these relate to the correlations for nonmetal hydrogen-bearing acids and oxyanions (Shock et al., 1997) represented by equations (21) and (29). The regressed values in Table 2 represent an improvement over the predictions of Akinfiev et al. (1994) relative to Figure 2; however, the error bars for $\left[\bar{V}_{S b(\mathrm{OH}) 3}^{o}\right]$ highlight the possibility that the correlations defined by Shock et al. (1997) also contain large uncertainties. Differences in predicted and experimental $\left[\Delta \bar{G}^{o}\right]$ determined in this study are compared on Figure 5A.

$\mathrm{Sb}(\mathrm{OH})_{4}{ }^{-1}$

The HKF equation of state parameters for this species were updated from the study of Akinfiev et al. (1994), which used the senarmontite solubility data of Popova (1975) at 25 and $200^{\circ} \mathrm{C}$. $\left[\Delta G_{f}^{o}\right]$ was fixed by the data at $25^{\circ} \mathrm{C},\left[\bar{S}^{o}\right]$ determined from regression, $\left[\Delta C_{P}^{o}\right]$ and $\left[\bar{V}^{o}\right]$ from the correlations represented by equations (21) and (29), and $[\omega]$ from equation (17). The results are shown on Figure 5B. 
A

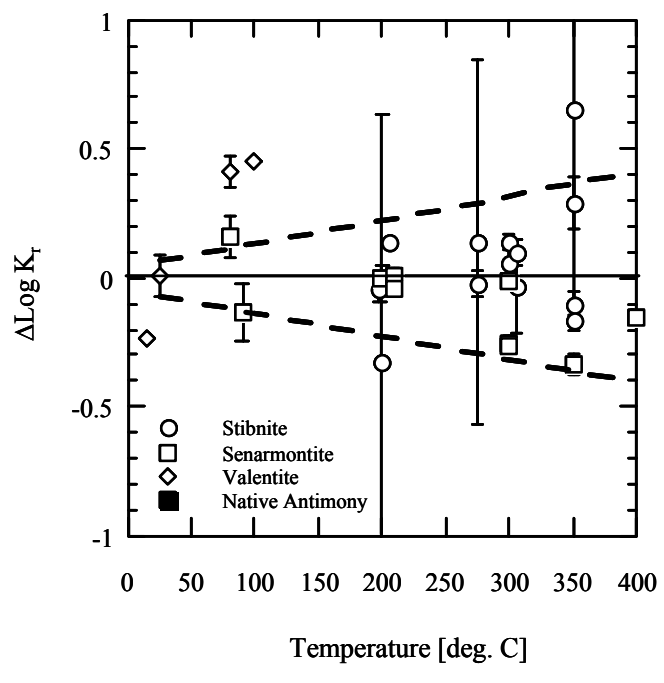

$\mathbf{C}$

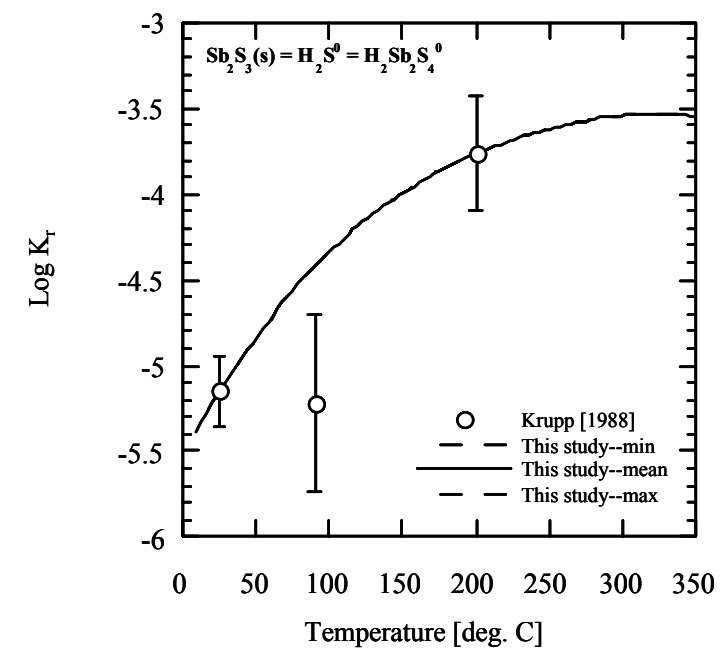

B
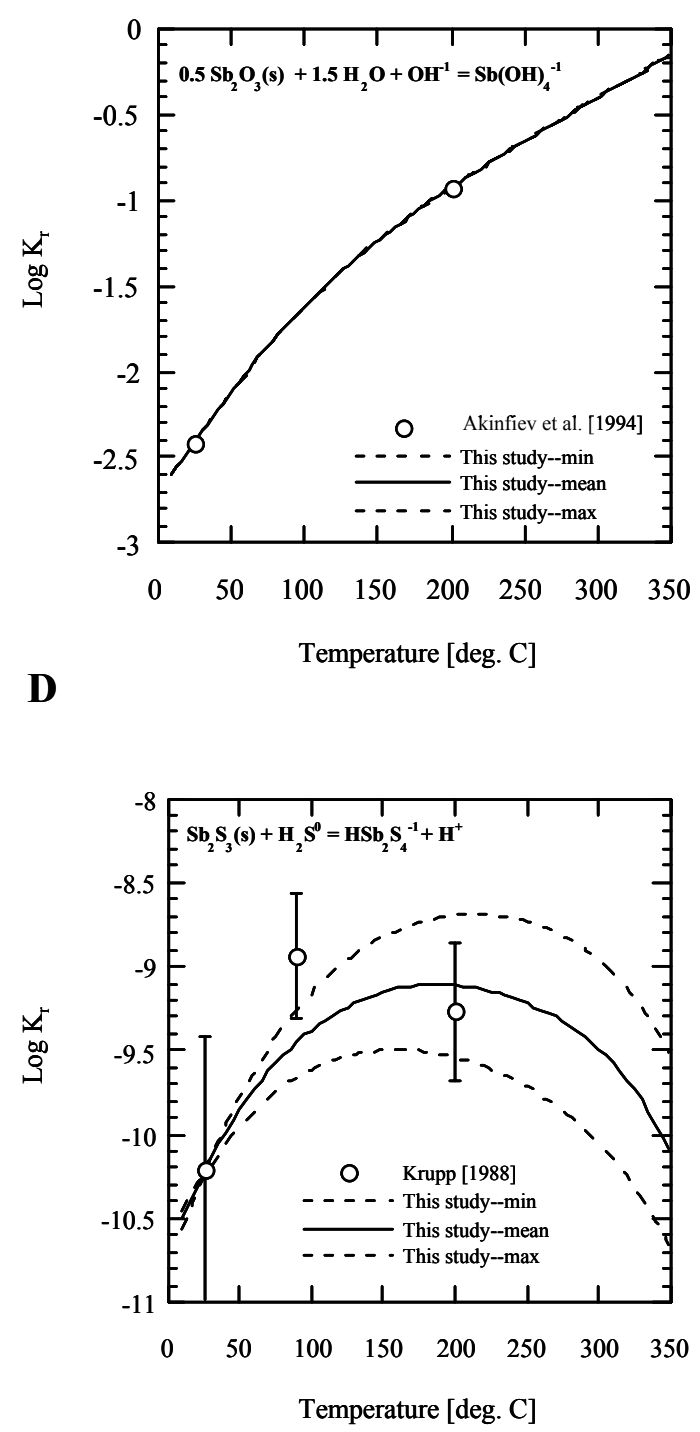

Fig. 5. Comparison between experimental data (symbols), predictions (solid lines), and calculated uncertainties (dashed lines) for aqueous antimony complexes: A) Differences between experimental and predicted equilibrium constants for $\mathrm{Sb}(\mathrm{OH})_{3}{ }^{0}$; B) Equilibrium constants for $\mathrm{Sb}(\mathrm{OH})_{4}{ }^{-1}$; C) Equilibrium constants for reaction (34); D) Equilibrium constants for reaction (35). 


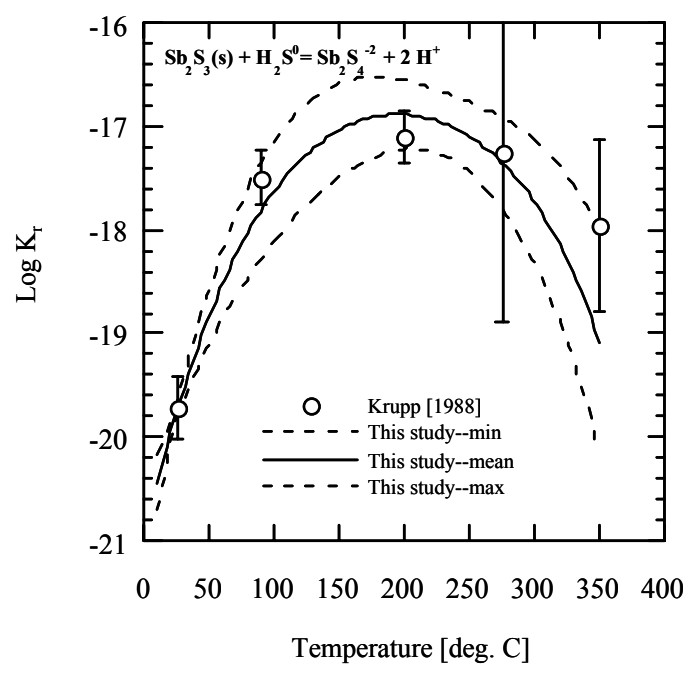

Fig. 5.E) Comparison between experimental data (symbols), predictions (solid lines), and calculated uncertainties (dashed lines) for reaction (36). 
$\mathrm{H}_{2} \mathrm{Sb}_{2} \mathrm{~S}_{4}{ }^{0}$

There is now general consensus that antimony sulfide species predominantly form as dimers under geologically realistic conditions. Spycher and Reed (1989) used least squares regression and multicomponent equilibrium calculations of existing stibnite solubility studies to show that least squares regression errors were minimized for the species $\mathrm{HSb}_{2} \mathrm{~S}_{4}^{-1}$ and $\mathrm{Sb}_{2} \mathrm{~S}_{4}^{-2}$. Tossell (1994) additionally used $a b$ initio quantum mechanical calculations to demonstrate that $\mathrm{H}_{2} \mathrm{Sb}_{2} \mathrm{~S}_{4}{ }^{0}$ is thermodynamically stable relative to its monomeric or trimeric forms. Finally, Krupp (1988) demonstrated the existence of $\mathrm{H}_{2} \mathrm{Sb}_{2} \mathrm{~S}_{4}{ }^{0}$ under neutral to acidic conditions from plots of $\log \mathrm{m}_{\mathrm{Sb}}$ versus $\mathrm{pH}$ and $\log \mathrm{TFS}$.

The HKF equation of state parameters for $\mathrm{H}_{2} \mathrm{Sb}_{2} \mathrm{~S}_{4}{ }^{0}$ were derived in this study as follows: First, $\left[\Delta \bar{G}_{f}^{o}\right]$ was fixed by the solubility reaction of stibnite at $25^{\circ} \mathrm{C}$ :

$$
\mathrm{Sb}_{2} \mathrm{~S}_{3}(\mathrm{~s})+\mathrm{H}_{2} \mathrm{~S}^{0}=\mathrm{H}_{2} \mathrm{Sb}_{2} \mathrm{~S}_{4}{ }^{0}
$$

Next, this reaction was assumed to be isocoulombic, allowing $\left[\bar{C}_{\mathrm{Pr}}^{o}\right]$ to be calculated from the heat capacities of stibnite and $\mathrm{H}_{2} \mathrm{~S}^{0}$. Finally, $\left[\bar{S}^{o}\right]$ was regressed from the experimental data at 25 and $200^{\circ} \mathrm{C}$, with $\left[\bar{V}^{o}\right]$ obtained from the correlation for nonmetal hydrogen-bearing acids and oxyanions

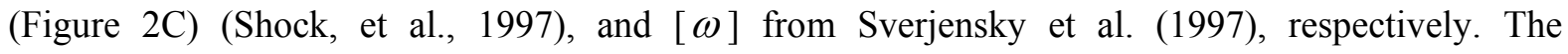
justification for excluding the datum at $90^{\circ} \mathrm{C}$ on Figure $5 \mathrm{C}$ is that it represents only one experimental measurement and results in a poor fit to the results at $200^{\circ} \mathrm{C}$.

$\mathrm{HSb}_{2} \mathrm{~S}_{4}^{-1}$

The importance of $\mathrm{HSb}_{2} \mathrm{~S}_{4}{ }^{-1}$ relative to $\mathrm{Sb}_{2} \mathrm{~S}_{4}{ }^{-2}$ at temperatures exceeding $200^{\circ} \mathrm{C}$ and $\mathrm{pH}>6$ is subject to debate. Krupp (1988) assumed $\mathrm{HSb}_{2} \mathrm{~S}_{4}{ }^{-1}$ controls stibnite solubility, but Akinfiev et al. (1994) hypothesized that $\mathrm{Sb}_{2} \mathrm{~S}_{4}^{-2}$ is more important because regression calculations showed that retrieving $\left[\bar{S}^{o}\right]$ and $\left[\bar{C}_{\mathrm{Pr}}^{o}\right]$ for $\mathrm{HSb}_{2} \mathrm{~S}_{4}{ }^{-1}$ from experiments at 275 and $350^{\circ} \mathrm{C}$ led to conflicting values at high and low temperatures. 
To better resolve this issue, the contribution due to $\mathrm{Sb}(\mathrm{OH})_{3}{ }^{0}$ and $\mathrm{H}_{2} \mathrm{Sb}_{2} \mathrm{~S}_{4}{ }^{0}$ were subtracted from the total solubility. Next, possible speciation scenarios were evaluated by plotting $\log \mathrm{m}_{\mathrm{Sb}}$ reported by Krupp (1988) as a function of $\mathrm{pH}$ along restricted ranges of log TFS $(+/-0.10 \mathrm{~mol} / \mathrm{kg}$ at $200^{\circ} \mathrm{C}$ and $+/-0.30 \mathrm{~mol} / \mathrm{kg}$ at $275^{\circ} \mathrm{C}$ ). The result is that both $\mathrm{HSb}_{2} \mathrm{~S}_{4}{ }^{-1}$ and $\mathrm{Sb}_{2} \mathrm{~S}_{4}{ }^{-2}$ are likely present at $200^{\circ} \mathrm{C}$, but only $\mathrm{Sb}_{2} \mathrm{~S}_{4}{ }^{-2}$ is consistent with the experimental results at $275^{\circ} \mathrm{C}$. Although this method was also extended to $350^{\circ} \mathrm{C}$, data were insufficient to identify which complex was present.

Based on these results, the HKF equation of state parameters for $\mathrm{HSb}_{2} \mathrm{~S}_{4}{ }^{-1}$ were derived from the experimental data reported by Krupp at 25,90 , and $200^{\circ} \mathrm{C} .\left[\Delta \bar{G}_{f}^{o}\right]$ was constrained by the following reaction at $25^{\circ} \mathrm{C}$ :

$$
\mathrm{Sb}_{2} \mathrm{~S}_{3}(\mathrm{~s})+\mathrm{H}_{2} \mathrm{~S}^{0}=\mathrm{HSb}_{2} \mathrm{~S}_{4}^{-1}+\mathrm{H}^{+}
$$

$\left[\bar{S}^{o}\right]$ was obtained from regression, and $\left[\bar{C}_{\mathrm{Pr}}^{o}\right],\left[\bar{V}^{o}\right]$, and $[\omega]$ from the same correlations used for $\mathrm{H}_{2} \mathrm{Sb}_{2} \mathrm{~S}_{4}{ }^{0}$.

The HKF equation of state parameters for $\mathrm{HSb}_{2} \mathrm{~S}_{4}{ }^{-1}$ and $\mathrm{H}_{2} \mathrm{Sb}_{2} \mathrm{~S}_{4}{ }^{0}$ represent significant improvement over the study of Akinfiev et al. (1994) relative to the correlations of Shock et al. (1997) (Table 2). Figure 5D shows the resulting equilibrium constant predictions for reaction (35). The first important feature of this plot is the large uncertainties associated with the re-computed data from the experiments of Krupp (1988). Although the error between prediction and experiment at $90^{\circ} \mathrm{C}$ is approximately $+/-0.5 \log$ units, the data are represented within the uncertainty envelopes provided by the dashed lines.

$\mathrm{Sb}_{2} \mathrm{~S}_{4}^{-2}$

The solubility of this species was obtained from the experiments of Krupp (1988) to $275^{\circ} \mathrm{C}$, based on the results presented above. $\left[\Delta \bar{G}_{f}^{o}\right]$ was obtained from the equilibrium constant at $25^{\circ} \mathrm{C}$ for the reaction: 


$$
\mathrm{Sb}_{2} \mathrm{~S}_{3}(\mathrm{~s})+\mathrm{H}_{2} \mathrm{~S}=\mathrm{Sb}_{2} \mathrm{~S}_{4}^{-2}+2 \mathrm{H}^{+}
$$

$\left[\bar{S}^{o}\right]$ and $\left[\bar{C}_{\mathrm{Pr}}^{o}\right]$ were obtained from regression on the experimental solubility constants, and $\left[\bar{V}^{o}\right]$ and $[\omega]$ were retrieved from the correlations for nonmetal hydrogen-bearing acids and oxyanions (Shock et al., 1997) and divalent anions (Shock and Helgeson, 1988), respectively. Although the position of $\mathrm{Sb}_{2} \mathrm{~S}_{4}{ }^{-2}$ in the correlation of Figure 2D represents additional justification for using the correlations of Shock et al. (1997) to describe nonmetal sulfur-bearing species, the error bars exceed $+/-90 \mathrm{cal} / \mathrm{mol}$ K. Similar uncertainties may exist in the other species represented on the Figure 2, highlighting the need to report uncertainties for the other species comprising the correlations.

The predicted equilibrium constants for reaction (36) are shown on Figure 5E. Assuming that the data at $350^{\circ} \mathrm{C}$ correspond to this aqueous species, the $\log \mathrm{K}_{\mathrm{r}}$ predictions at the highest temperature are underestimated.

\section{Aqueous Mercury Complexes}

$\mathrm{Hg}(\mathrm{OH})_{2}{ }^{0}$

The HKF equation of state parameters for $\mathrm{Hg}(\mathrm{OH})_{2}{ }^{0}$ were calculated from the solubility of $\mathrm{HgO}(\mathrm{s})$ (montroydite) at $90^{\circ} \mathrm{C}$ (Khodakovsky and Shinkina, 1981):

$$
\mathrm{HgO}(\mathrm{s})+\mathrm{H}_{2} \mathrm{O}=\mathrm{Hg}(\mathrm{OH})_{2}{ }^{0} .
$$

$\left[\Delta \bar{G}_{f}^{o}\right]$ was calculated by regression after obtaining $\left[\bar{C}_{\mathrm{Pr}}^{o}\right]$ from the isocoulombic reaction:

$$
\mathrm{Hg}(\mathrm{HS})_{2}{ }^{0}+2 \mathrm{OH}^{-1}=\mathrm{Hg}(\mathrm{OH})_{2}{ }^{0}+2 \mathrm{HS}^{-1}
$$

$\left[\bar{S}^{o}\right]$ from equation (21), $\left[\bar{V}^{o}\right]$ from equation (22), and $[\omega]$ from Sverjensky et al. (1997). The resulting predictions are shown on Figure 6A. 
$\mathbf{A}$

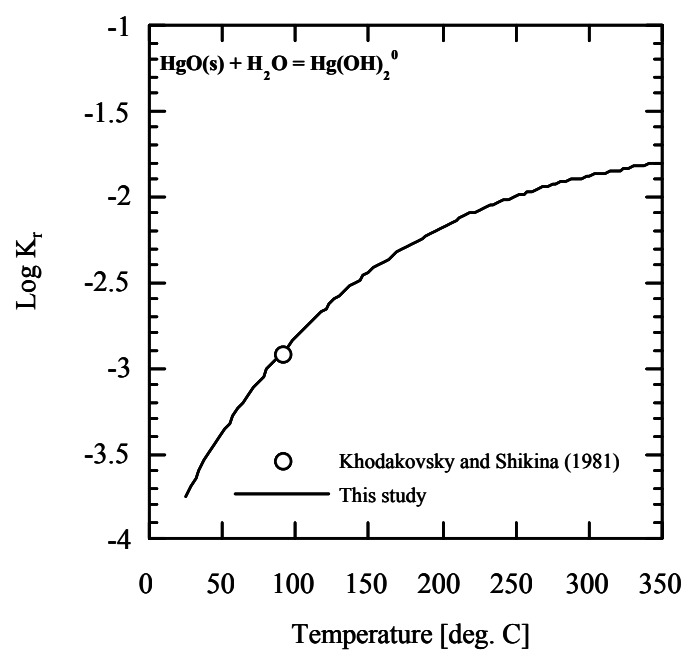

C

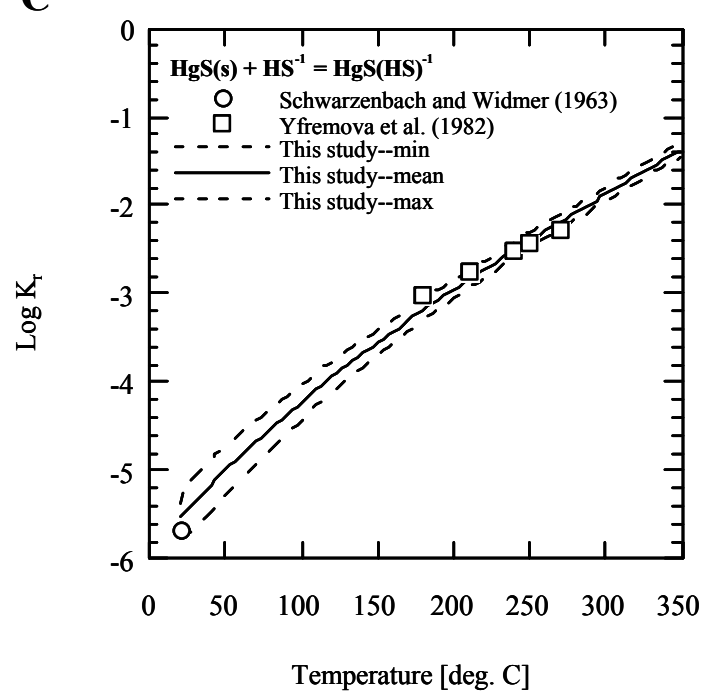

B

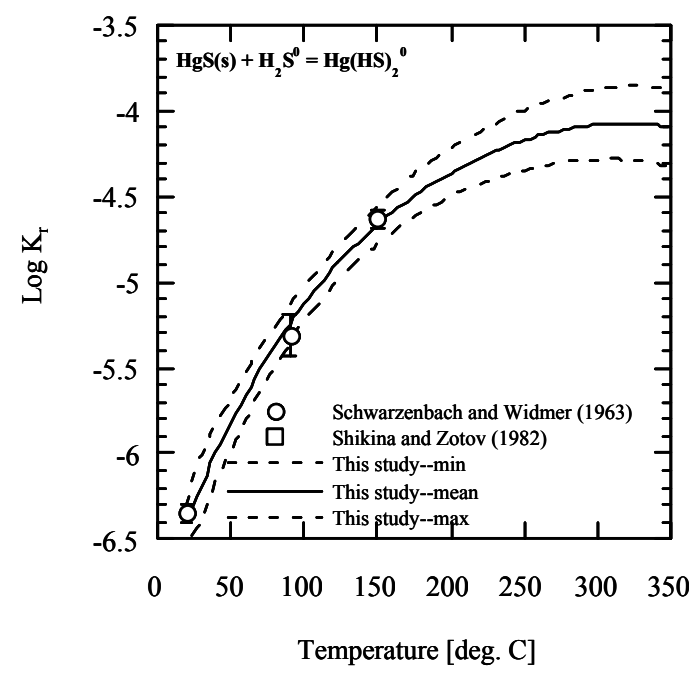

D

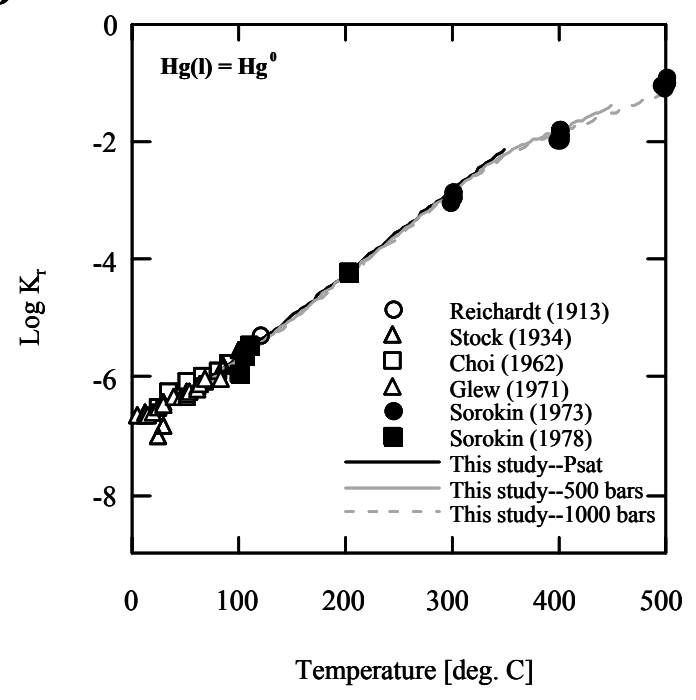

Fig. 6. Comparison between experimental data (symbols), predictions (solid lines), and calculated uncertainties (dashed lines) for aqueous mercury complexes: A) Equilibrium constants for reaction (37); B) Equilibrium constants for reaction (39); C) Equilibrium constants for reaction (40); D) Equilibrium constants for reaction (41). 
$\mathrm{Hg}(\mathrm{HS})_{2}{ }^{0}$

There is some debate as to the stoichiometry of mercury sulfide complexes (Krupp, 1988). Because Barnes et al. (1967) worked with high total sulfide concentrations ( $\Sigma \mathrm{S}=0.38-3.7$ molal), and Yefremova et al. (1982) observed a transition from singly coordinated to doubly coordinated species at $\Sigma \mathrm{S}=1.0$ molal, the experiments of Barnes et al. (1967) are unrepresentative of conditions in many hydrothermal deposits. Consequently, the HKF equation of state parameters for $\mathrm{Hg}(\mathrm{HS})_{2}{ }^{0}$ were obtained from the solubility constants reported by Schwarzenbach and Widmer (1963) (cinnabar) and Shikina et al. (1982) (metacinnabar) for the following reaction:

$$
\mathrm{HgS}(\mathrm{s})+\mathrm{H} 2 \mathrm{~S} 0=\mathrm{Hg}(\mathrm{HS})_{2}{ }^{0}
$$

where $\mathrm{HgS}(\mathrm{s})$ is either metacinnabar or cinnabar. $\left[\Delta \bar{G}_{f}^{o}\right]$ and $\left[\bar{S}^{o}\right]$ were obtained from regression calculations, $\left[\bar{C}_{\mathrm{Pr}}^{o}\right]$ from equation (21), $\left[\bar{V}^{o}\right]$ from equation (22), and $[\omega]$ from Sverjensky et al. (1997). The resulting predictions are shown on Figure 6B.

$\operatorname{HgS}(H S)^{-1}$

The HKF equation of state parameters for $\mathrm{HgS}(\mathrm{HS})^{-1}$ were calculated from the solubility experiments of Schwarzenbach and Widmer (1963) and Yfremova et al. (1982) using the solubility constant reported for the following reaction:

$$
\mathrm{HgS}(\mathrm{s})+\mathrm{HS}^{-1}=\mathrm{HgS}(\mathrm{HS})^{-1} .
$$

$\left[\Delta \bar{G}_{f}^{o}\right]$ and $\left[\bar{S}^{o}\right]$ were obtained from regression calculations, $\left[\bar{C}_{\mathrm{Pr}}^{o}\right]$ from equation $(21),\left[\bar{V}^{o}\right]$ from equation (22), and $[\omega]$ from equation (17). The resulting predictions are shown on Figure 6C.

$\mathrm{Hg}^{0}$

In addition to hydroxide and sulfide complexes, mercury can be transported as a hydrated aqueous species (Reichardt, 1913; Stock, 1934; Choi, 1962; Glew, 1971; Sorokin, 1973 and 1978). 
$\left[\Delta \bar{G}_{f}^{o}\right]$ was calculated in this study from the average solubility constant reported at $25^{\circ} \mathrm{C}$ for the following reaction:

$$
\operatorname{Hg}(1)=\mathrm{Hg}^{0}
$$

$\left[\bar{S}^{o}\right],\left[\bar{C}_{\mathrm{Pr}}^{o}\right],\left[\bar{V}^{o}\right]$, and $[\omega]$ were then obtained from regression of experimental data. The Born parameter $[\omega]$ derived from this analysis is close to the value used by Sverjensky et al. (1997) for neutral aqueous species, consistent with the theoretical framework of the HKF equation of state. Predicted values for the solubility constant of reaction (41) are also well desccribed (Fig. 6D).

\section{Aqueous Silver Complexes}

\section{$\operatorname{Ag}(\mathrm{OH})^{0}$}

The HKF equation of state parameters for $\operatorname{Ag}(\mathrm{OH})^{0}$ were calculated from the solubility experiments of Kozlov et al. (1985) using the solubility constant for the following reaction:

$$
0.5 \mathrm{Ag}_{2} \mathrm{O}(\mathrm{s})+0.5 \mathrm{H}_{2} \mathrm{O}=\mathrm{Ag}(\mathrm{OH})^{0} \text {. }
$$

$\left[\Delta \bar{G}_{f}^{o}\right]$ was obtained from the experiments at $25^{\circ} \mathrm{C},\left[\bar{S}^{o}\right]$ from regression calculations, $\left[\bar{C}_{\mathrm{Pr}}^{o}\right]$ from equation (21), $\left[\bar{V}^{o}\right]$ from the correlation for monovalent ions (Sverjensky et al., 1997), and [ $\omega$ ] from Sverjensky et al. (1997). The resulting predictions are shown on Figure $7 \mathrm{~A} .\left[\bar{C}_{\mathrm{Pr}}^{o}\right]$ and $\left[\bar{V}^{o}\right]$ are compared to equation 22 on Figure 2B.

$\operatorname{Ag}(H S)^{0}$

Solubility measured in the presence of the $\mathrm{Ag}_{2} \mathrm{~S}(\mathrm{~s})$ has been found to exhibit no $\mathrm{pH}$ dependence at a pH < 4 (Melent'yev et al., 1969; Sugaki et al., 1987; Wood et al., 1987). Based on the fact that the aqueous species $\mathrm{Ag}(\mathrm{HS})_{2}{ }^{-1}$ has been shown to exist (Gammons and Barnes, 1989), it may expected that the species producing this trend is $\operatorname{Ag}(\mathrm{HS})_{2}{ }^{0}$; however, Gammons and Barnes (1989) demonstrated that total sulfide concentrations in each set of experiments exhibiting this trend 

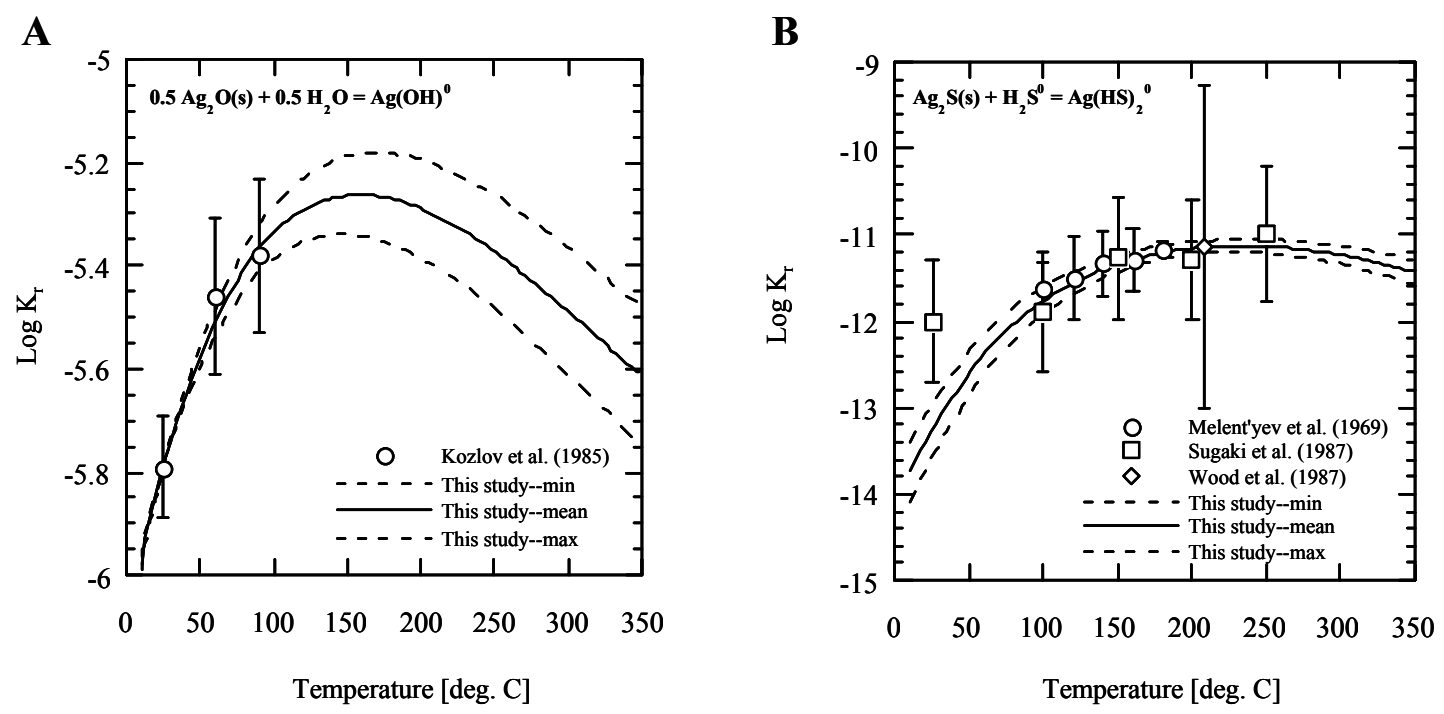

C

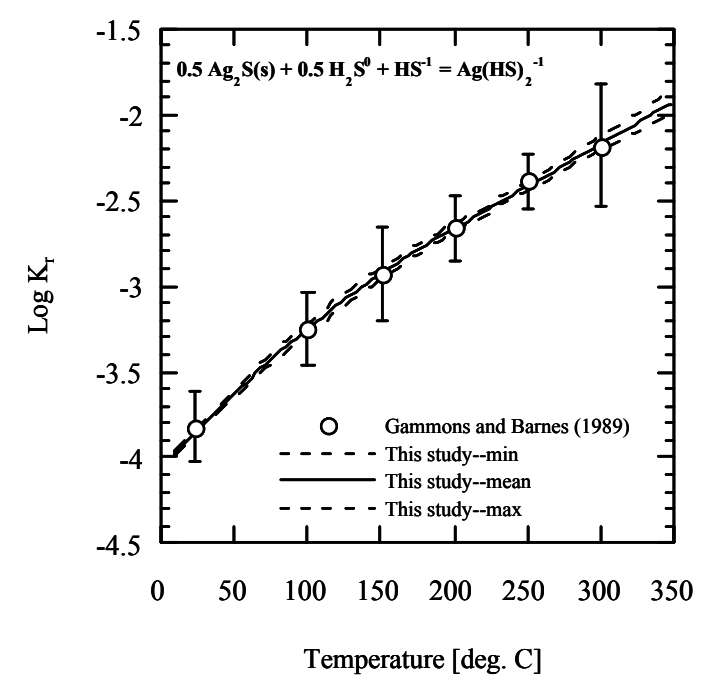

Fig. 7. Comparison between experimental data (symbols), predictions (solid lines), and calculated uncertainties (dashed lines) for aqueous silver complexes: A) Equilibrium constants for reaction (42); B) Equilibrium constants for reaction (43); C) Equilibrium constants for reaction (44). 
were not varied enough to ascertain the silver complex responsible for solubility. Combining the data of the various experiments at $200^{\circ} \mathrm{C}$, they found that a plot of $\log \mathrm{a}_{\mathrm{H} 2 \mathrm{~S}}$ versus $\log \mathrm{m}_{\mathrm{Ag}}$ produced a linear least square fit slope of +0.25 (a slope of +0.5 would be representative of the aqueous species $\left.\operatorname{Ag}(\mathrm{HS})^{0}\right)$

To reconcile the experiments of Melent'yev et al. (1969), Sugaki et al. (1987), and Wood et al. (1987), experimental results were re-speciated in this study. After subtracting the contribution due to the aqueous species $\mathrm{Ag}(\mathrm{HS})_{2}{ }^{-1}$, it was found that the $\mathrm{pH}$ experiments of Wood et al. (1987) with the lowest initial $\mathrm{pH}$ produced an observed slope of +0.5 when compared with the data of Sugaki et al. (1987) at $200^{\circ} \mathrm{C}$. Due to the possibility of experimental interference in some experimental runs of Wood et al. (1987) (Gammons and Barnes, 1989), only those data at $200^{\circ} \mathrm{C}$ that conformed to the +0.5 slope were included in the regression calculations. The experimental results of Schwarzenbach and Widmer at $20^{\circ} \mathrm{C}$ were omitted, because they produced a solubility three orders of magnitude different than the trend shown on Figure 7B for the reaction:

$$
0.5 \mathrm{Ag}_{2} \mathrm{~S}(\mathrm{~s})+0.5 \mathrm{H}_{2} \mathrm{~S}=\mathrm{Ag}(\mathrm{HS})^{0} .
$$

$\left[\Delta \bar{G}_{f}^{o}\right]$ and $\left[\bar{S}^{o}\right]$ were obtained from regression calculations, $\left[\bar{C}_{\mathrm{Pr}}^{o}\right]$ from equation (21), and $\left[\bar{V}^{o}\right]$ from the correlation for monovalent ions (Sverjensky et al., 1997). The resulting predictions are shown on Figure 7B. [ $\left.\bar{C}_{\mathrm{Pr}}^{o}\right]$ and $\left[\bar{V}^{o}\right]$ are well described by equation 22 as shown on Figure $2 \mathrm{~B}$.

$\operatorname{Ag}(H S)_{2}^{-1}$

The HKF equation of state parameters for $\operatorname{Ag}(\mathrm{HS})_{2}{ }^{-1}$ were calculated from the solubility experiments of Gammons and Barnes (1989) using the solubility constant for the following reaction:

$$
0.5 \mathrm{Ag}_{2} \mathrm{~S}(\mathrm{~s})+0.5 \mathrm{H}_{2} \mathrm{~S}=\mathrm{Ag}(\mathrm{HS})^{0} \text {. }
$$

$\left[\Delta \bar{G}_{f}^{o}\right]$ was obtained from the experiments at $25^{\circ} \mathrm{C},\left[\bar{S}^{o}\right]$ and $\left[\bar{C}_{\mathrm{Pr}}^{o}\right]$ from regression calculations, $\left[\bar{V}^{o}\right]$ estimated from the standard partial molal volume of $\mathrm{Au}(\mathrm{HS})^{0}$ and the difference in ionic radius 
between $\mathrm{Ag}^{+}$and $\mathrm{Au}^{+}$, and $[\omega]$ from equation (17). The resulting predictions are shown on Figure 7C. $\left[\bar{C}_{\mathrm{Pr}}^{o}\right]$ and $\left[\bar{V}^{o}\right]$ are well described by equation 22 as demonstrated on Figure $2 \mathrm{~B}$.

\section{Phase Relationships in the System Fe-Au-As-Sb-Hg-Ag-S-O-H-Cl}

Predicted standard partial molal Gibbs free energies of formation of aqueous and mineral phases compiled in this study and in the SUPCRT database (Johnson et al., 1992) were used to construct oxygen fugacity-temperature diagrams to gain an improved understanding of the conditions leading to mineralization in the Carlin-type gold deposits. In order to perform the calculations, a temperature and pressure regime was selected that assumes a temperature gradient of approximately $40^{\circ} \mathrm{C} / \mathrm{km}$ and a lithostatic pressure. At $5.4 \mathrm{~km}$, this corresponds to a temperature of approximately $225^{\circ} \mathrm{C}$ and 800 bars, similar to conditions inferred from fluid inclusions for the Carlin deposit (Kuehn and Rose, 1995). A total sulfur concentration of $0.05 \mathrm{~m}$ was assumed during diagram construction, also based on fluid inclusion estimates.

The results of this analysis are shown on Figures $8 \mathrm{~A}$ through $8 \mathrm{E}$, from which it can be seen that inferred main-stage mineralization in the Carlin deposit (point A) is within the stability fields of the following minerals: pyrite $\left(\mathrm{FeS}_{2}\right)$; native gold $(\mathrm{Au})$; arsenopyrite $(\mathrm{FeAsS})$; stibnite $\left(\mathrm{Sb}_{2} \mathrm{~S}_{3}\right)$; cinnabar $(\mathrm{HgS})$; and argentite $\left(\mathrm{Ag}_{2} \mathrm{~S}\right)$. Also, a decline in temperature (at a constant oxygen fugacity from Point A) leads to a reduction in solubility of all the elements. As shown on the figures, changes in oxidation state have the greatest effect on gold, arsenic and mercury solubility. In fact, because changes in arsenic mineral stability and solubility are so sensitive to the oxidation state of the system, arsenic minerals are likely an important indicator of redox conditions during ore formation. An additional observation is that mineral solubility in the vicinity of Point $\mathrm{A}$ is predominantly described by sulfide complexes, implying that sulfidation of host rock iron is an effective mechanism promoting mineralization. Although this result is consistent with previou s model results (Hofstra et al., 1991; 

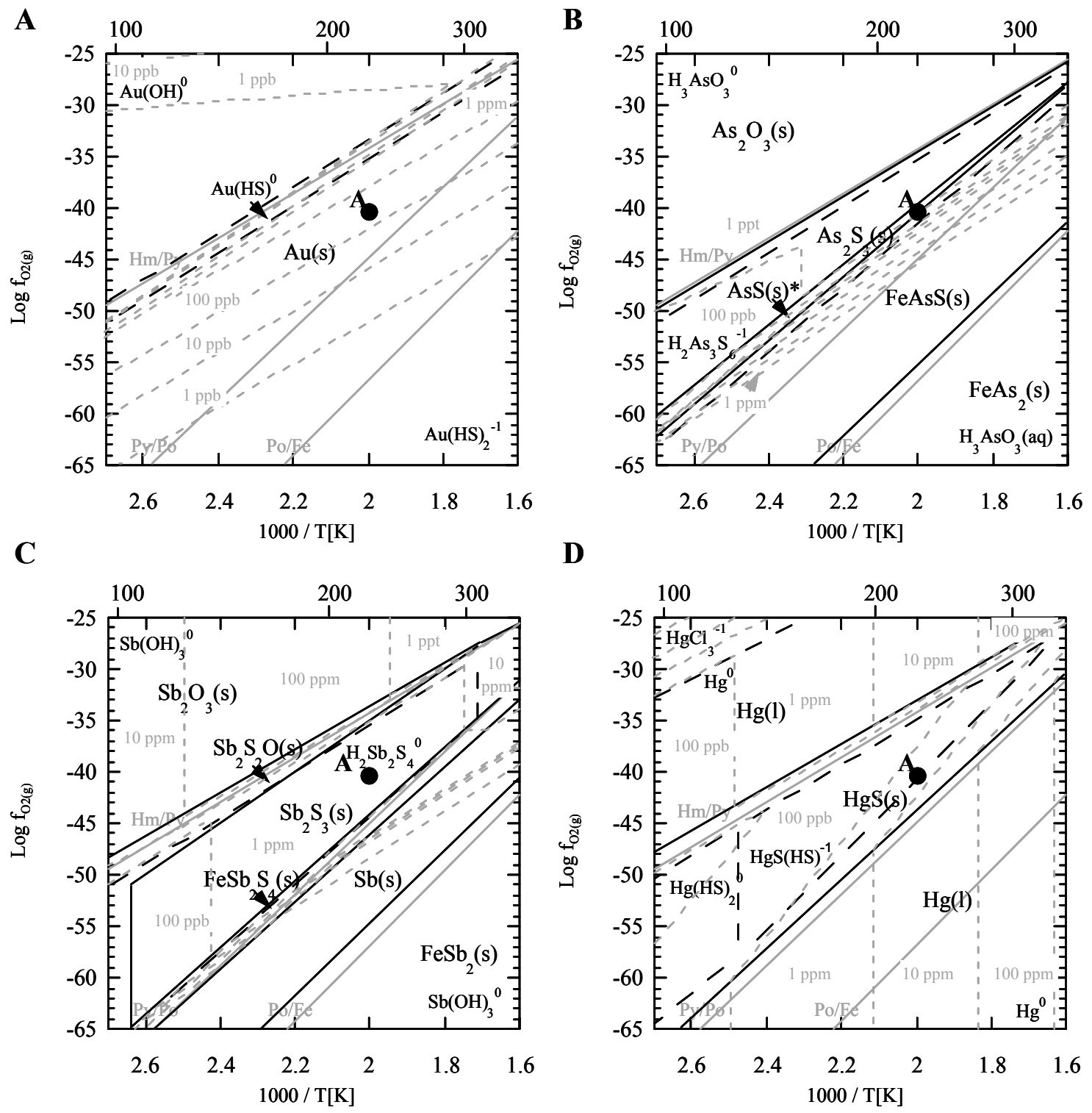

D

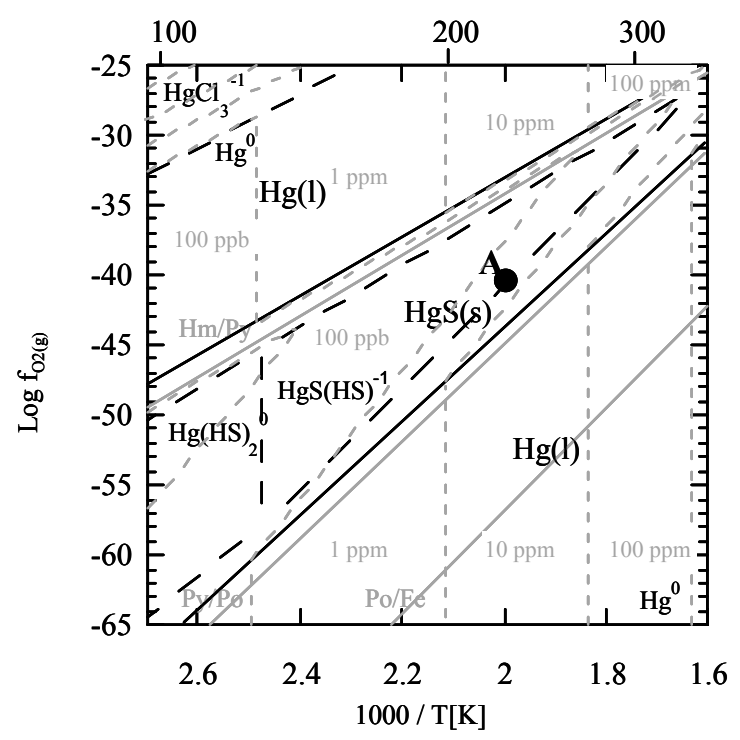

Fig. 8. Solid phase stability fields (solid lines), aqueous stability fields (long dashed lines), and solubility contours (short dashed lines) for temperature and $\mathrm{f}_{\mathrm{O} 2(\mathrm{~g})}$ conditions where Point $\mathrm{A}$ is inferred from fluid inclusions from Carlin-type gold deposits (see text). Total sulfur concentration is $0.05 \mathrm{~m}, \mathrm{pH}$ is 5.0, and pyrrhotite activity is equal to 0.5 (Barker and Parks, 1986). A) Gold phase relations; B) Arsenic phase relations; C) Antimony phase relations; D) Mercury phase relations. 


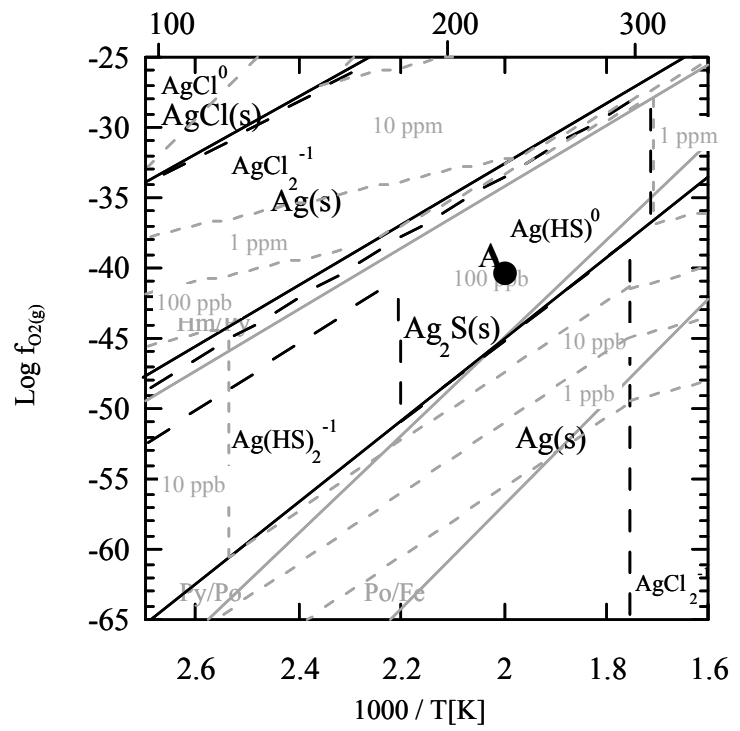

Fig. 8.E) Solid phase stability fields (solid lines), aqueous stability fields (long dashed lines), and solubility contours (short dashed lines) for Silver phases for temperature and $\mathrm{f}_{\mathrm{O} 2(\mathrm{~g})}$ conditions where Point $\mathrm{A}$ is inferred from fluid inclusions from Carlin-type gold deposits (see text). Total sulfur concentration is $0.05 \mathrm{~m}, \mathrm{pH}$ is 5.0 , and pyrrhotite activity is equal to 0.5 (Barker and Parks, 1986). 
Ilchik and Barton, 1997), it does not explain observed mineral paragenesis, in which orpiment, realgar, and stibnite are late-stage minerals.

A sensitivity test was undertaken using a total sulfur concentration of $0.01 \mathrm{~m}$. The results of this analysis is that arsenic and antimony are predicted to be transported as hydroxide complexes at $225^{\circ} \mathrm{C}$ under lower sulfide concentrations. Although host rock sulfidation still promotes arsenopyrite deposition via:

$$
\mathrm{H}_{3} \mathrm{As}_{3} \mathrm{O}_{3}{ }^{0}+\mathrm{FeS}_{2}(\mathrm{~s})=\mathrm{FeAsS}(\mathrm{s})+0.5 \mathrm{H}_{2} \mathrm{O}+5 / 4 \mathrm{O}_{2}{ }^{0}
$$

antimony solubility is enhanced by the following reaction:

$$
2 \mathrm{Sb}(\mathrm{OH})_{3}{ }^{0}+3 \mathrm{H}_{2} \mathrm{~S}^{0}=\mathrm{Sb} 2 \mathrm{~S}_{3}(\mathrm{~s})+6 \mathrm{H}_{2} \mathrm{O} .
$$

This difference in speciation may explain why antimony passes through the system during sulfidation, ultimately depositing later in the paragenetic sequence.

\section{Conclusions}

The HKF equation of state parameters for gold, arsenic, antimony, mercury, and silver sulfide and hydroxide complexes were derived within the framework of a consistent thermodynamic database. Because many of the studies reporting equilibrium constants for the dissolution of the associated minerals used conflicting thermodynamic data (especially for $\mathrm{H}_{2} \mathrm{~S}^{0}$ and $\mathrm{HS}^{-}$) the parameters for these two aqueous species were updated in the re-calculation. Regression calculations were then used to extract the nine HKF equation of state parameters.

Several limitations to predicting the behavior of these metals under hydrothermal conditions were identified in this study. For example, the HKF equation of state has difficulty predicting partial molal volumes and heat capacities of volatile neutral species near the critical point of water. Also, the

g-correction developed by Tanger and Helgeson (1988) and Shock et al. (1992) may be species dependent. There are large uncertainties associated with the correlation algorithms used to predict standard partial molal properties in the absence of sufficient experimental data. Finally, there are 
significant gaps in existing experimental data, such as the nature of arsenic sulfide complexes and the true solubility of gold and silver as bisulfide complexes.

An important finding of this study is that the standard partial molal thermodynamic properties

of gold, arsenic, antimony, mercury, and silver sulfide and hydroxide complexes can be described by linear correlations. Also, arsenic and antimony minerals are key indicators to chemical conditions during mineralization. This is exemplified by changes in the total sulfide concentration, where a concentration less than $0.05 \mathrm{~m}$ is required to explain stibnite deposition in the paragenetic sequence. Additional clues to metallogenesis can be determined using reaction-path calculations and the equation of state parameters derived in this study.

\section{References}

Akinfiev N.N. and Zotov A.V. (2001) Thermodynamic description of chloride, hydrosulfide, and hydroxo complexes of $\mathrm{Ag}(\mathrm{I}), \mathrm{Cu}(\mathrm{I})$, and $\mathrm{Ag}(\mathrm{I})$ at temperatures of $25-500^{\circ} \mathrm{C}$ and pressures of 1-2000 bars. Geochem. Intern. 39, 990-1006.

Akinfiev N.N., Zotov A.V., and Nikonorov A.P. (1992) Thermodynamic analysis of equilibria in the system As(III)-S(II)-O-H. Geochem. Intern. 29, 109-121.

Akinfiev N.N., Zotov A.V., and Shikina N.D. (1994) Experimental investigation and thermodynamic correlation in the $\mathrm{Sb}(\mathrm{III})-\mathrm{S}(\mathrm{II})-\mathrm{O}-\mathrm{H}$ system. Geochem. Intern. 31, 27-40.

Anderson, E. and Storey L.G. (1922) Studies on certain physical properties of arsenic trioxide in water solutions. J. Amer. Chem. Soc. 45, 1102-1105.

Arehart, G.B., 1996. Characteristics and origin of sediment-hosted disseminated gold deposits: A review. Ore Geology Reviews, 11, 383-403. 
Arehart, G.B., Chryssoulis, S.L., and Kesler, S.E. (1993) Gold and arsenic in iron sulfides from sediment-hosted disseminated gold deposits; implications for depositional processes. Econ. Geol. 88, 171-185.

Baes C.F. and Mesmer R.E. (1976) The Hydrolysis of Cations. Wiley.

Bagby, W.C. and Berger, B.R. (1985) Geological characteristics of sediment-hosted disseminated precious-metal deposits in the western United States. In Geology and Geochemistry of epithermal systems. Rev. Econ. Geol. 2, 169-202.

Barbero J.A., McCurdy K.G., and Tremaine P.R., (1982) Apparent molal heat capacities and volumes of aqueous hydrogen sulfide and sodium hydrogen sulfide near $25^{\circ} \mathrm{C}$ : The temperature dependence of $\mathrm{H}_{2} \mathrm{~S}$ ionization. Can. J. Chem. 60, 1872-1880.

Barker W.W. and Parks T.C. (1986) The thermodynamic properties of pyrrhotite and pyrite: a reevaluation. Geochim. Cosmochim. Acta 50, 2185-2194.

Barnes, H.L., Romberger, S.N., and Stemprok, M. (1967) Ore solution chemistry III. Solubility of HgS in sulfide solutions. Econ. Geol. 62, 957-982.

Barton M.D. (1980) The Ag-Au-S System. Econ. Geol. 75, 303-316.

Belevantsev V.I., Pescchevskii, and Shamovskaya G.I. (1981) Gold(I) complexes in aqueous solution. Isvest. sib. Otd. Nauk SSSR, Ser. Khim 1, 81-87.

Benning L.G. and Seward T.M. (1996) Hydrosulphide complexing of Au(I) in hydrothermal solutions from $150-400^{\circ} \mathrm{C}$ and 500-1500 bar. Geochim. Cosmochim. Acta 60, 1849-1871.

Choi, S.S. and Tuck, D.G. (1962) A neutron activation study of the solubility of mercury in water. $J$. Chem. Soc. 797, 4080-4088.

Cline, J.S. and Hofstra, A.A. (2000) Ore-fluid evolution at the Gethcell Carlin-type gold deposit, Nevada, USA. Eur. J. Mineral. 12, 195-212.

Dadze, T.P., Akhmedzhanova, G.M., Kashirtseva, G.A., Orluv, R.Y. (2001) Solubility of gold in sulfide-containing aqueous solutions at $\mathrm{T}=300^{\circ} \mathrm{C} . \mathrm{J}$. Mol. Liq. 91, 99-102. 
De Cugnac-Pailliotet A. and Pouradier J. (1972) Proprietes thermodynamiques du sulfure d'or. C.R. Acad. Sc., Ser. C. 275, 551-554.

Driesner T., Seward T.M., and Tironi I.G. (1998) Molecular dynamics simulation study of ionic hydration and ion association in dilute and 1 molal aqueous solutions from ambient to supercritical conditions. Geochim. Cosmochim. Acta 62, 3095-3107.

Drummond S.E. (1981) Boiling and mixing of hydrothermal fluids: chemical effects on mineral precipitation. Ph.D. thesis, Pennsylvania State University.

Eary L. E. (1992) The solubility of amorphous $\mathrm{As}_{2} \mathrm{~S}_{2}$ from 25 to $90^{\circ} \mathrm{C}$. Geochim. Cosmochim. Acta 56, 2267-2280.

Ellis A.J. and Giggenbach W. (1971) Hydrogen sulphide ionization and sulphur hydrolysis in high temperature solution. Geoch. Cosmochim. Acta 35, 247-260.

Ellis A.J. and McFadden I.M. (1972) Partial molal volumes of ions in hydrothermal solutions. Geochim. Cosmochim. Acta 36, 413-426.

Fleet, M.E. and Knipe, S.W. (2000) Solubility of native gold in H-O-S fluids at 100-400C and high $\mathrm{H}_{2} \mathrm{~S}$ content. J. Sol. Chem. 29, 1143-1157.

Gammons, C.H. and Barnes, H.L. (1989) The solubility of $\mathrm{Ag}_{2} \mathrm{~S}$ in near-neutral aqueous sulfide solutions at 25 to $300^{\circ}$ C. Geochim. Cosmochim. Acta 53, 279-290.

Gibert F., Pascal M.L., and Pichavant M. (1998) Gold solubility and speciation inhydrothermal solutions: Experimental study of the stability of hydrosulphide complex of gold $\mathrm{Au}(\mathrm{HS})^{0}$ at 350 to $450^{\circ} \mathrm{C}$ and 500 bars. Geochim. Cosmochim. Acta 62, 2931-2947.

Glew, D.N. and Hames, D.A. (1971) Aqueous nonelectrolyte solutions. Part X. Mercury solubility in water. Canad. J. Chem. 49, 3114-3118.

Hayashi K. and Ohmoto H. (1991) Solubility of gold in NaCl- and $\mathrm{H}_{2} \mathrm{~S}$-bearing aqueous solutions at 250-350 C. Geochim. Cosmochim. Acta 55, 2111-2126. 
Helgeson H.C., Kirkham D.H., and Flowers G.C. (1981) Theoretical prediction of the thermodynamic behavior of aqueous electrolytes at high pressures and temperatures: IV. Calculation of the activity coefficients, osmotic coefficients, and apparent molal and standard and relative partial molal properties to $600^{\circ} \mathrm{C}$ and $5 \mathrm{~kb}$. Amer. J. Sci. 281, 1249-1516.

Helz G.R., Tossell J.A., Charnock J.M., Pattrick R.A.D., Vaughan D.J., and Garner C.D. (1995) Oligomerization in As (III) sulfide solutions; theoretical constraints and spectroscopic evidence. Geochim. Cosmochim. Acta 59, 4591-4604.

Hnedkovsky L., Wood R.H., and Majer V. (1996) Volumes of solutions of $\mathrm{CH}_{4}, \mathrm{CO}_{2}, \mathrm{H}_{2} \mathrm{~S}$, and $\mathrm{NH}_{3}$ at temperatures from $298.15 \mathrm{~K}$ to $705 \mathrm{~K}$ and pressures to $35 \mathrm{MPa}$. J. Chem.Thermodyn. 28, $125-142$.

Hnedkovsky L. and Wood, R.H. (1997) Apparent molar heat capacities of aqueous solutions of $\mathrm{CH}_{4}$, $\mathrm{CO}_{2}, \mathrm{H}_{2} \mathrm{~S}$, and $\mathrm{NH}_{3}$ at temperatures from $304 \mathrm{~K}$ to $704 \mathrm{~K}$ at a pressure of $28 \mathrm{MPa}$. J. Chem.Thermodyn. 29, 731-747.

Hofstra, A.H., Leventhal, J.S., Northrop, G.P., Landis, G.P., Rye, R.O., Birak, D.J., and Dahl, A.R. (1991) Genesis of sediment-hosted disseminated-gold deposits by fluid mixing and sulfidation: Chemical-reaction-path modeling of ore-depositional processes documented in the Jerritt Canyon district, Nevada. Geol. 19, 36-40.

Ilchik, R.P. and Barton, M.D. (1997) An amagmatic origin of Carlin-type gold deposits. Econ. Geol. 92, 269-288.

Johnson, J.W. and Norton D. (1991) Critical phenomena in hydrothermal systems: state, thermodynamic, electrostatic, and transport properties of $\mathrm{H} 2 \mathrm{O}$ in the critical region. Am. J. Sci. 291, 541-648.

Johnson J.W., Oelkers E.H., and Helgeson H.C. (1992) SUPCRT92; a software package for calculating the standard molal thermodynamic properties of minerals, gases, aqueous species, and reactions from 1 to 5000 bar and 0 to 1000 degrees C. Comput. Geosci. 18, 899-947. 
Khodakovsky, I.L. and Shikina, N.D. (1981) The role of carbonate complexes in mercury transport in hydrothermal solutions (experimental studies and thermodynamic analysis. Geochem. Int. 18, $32-43$.

Kozintseva T.N. (1964) Solubility of hydrogen sulfide in water at elevated temperatures. Geochem. Intern., 750-756.

Kozlov, V.K., Kuznetsov, V.N., and Khodakovsky, I.L. (1983) The thermodynamic parameters of $\mathrm{Ag}_{2} \mathrm{O}(\mathrm{s})$ and silver(I) hydroxy complexes in aqueous solutions at elevated temperatures. Geochem. Int. 20, 137-149.

Krupp, R. (1988) Physicochemical aspectes of mercury metallogenesis. Chem Geol. 69, 345-356.

Krupp R.E. (1988) Solubility of stibnite in hydrogen sulfide solutions, speciation, and equilibrium constants, from 25 to $350^{\circ} \mathrm{C}$. Geochim. Cosmochim. Acta 52, 3005-3015.

Kuehn, C.A. and Rose, A.W. (1995) Carlin gold deposits, Nevada; origin in a deep zone of mixing between normally pressured and overpressured fluids. Econ. Geol. 90, 17-36.

Kulik D.A., Dmitrieva S.V., Chudnenko K.V., Karpov I.K., Sinitsyn V.A., Aja S.U., Khordorivski M.S., and Shibetsky Y.A. (1997) Selektor-A: Integrated Program and Database to Calculate Environmental Geochemical Equilibria by Gibbs Energy Minimization. User's Manual. Brooklyn-Kiev.

Kryukov P.A. and Starostina L.I. (1978) The first ionization constants of hydrogen sulfide at temperatures $150^{\circ}$ C. Izvestija Sibirskogo Otdelenia AN SSSR 14, 87-93.

Linke W.F. (1958) Solubilities of Inorganic and Metal-Organic Compounds. 4th ed., 1, pp. 234-240. ACS.

Maier C.G. and Kelley K.K. (1932) An equation for the representation of high temperature heat content data. J. Amer. Chem. Soc. 54, 3243-3246.

Melent'yev B.N., Ivanenko, V.V., and Pamfilova, L.A. (1969) Solubility of some ore-forming sulfides under hydrothermal conditions. Geochem. Intern. 6, 416-460. 
Mironova G.D. and Zotov A.V. (1981) Solubility studies of the stability of As (III) sulfide complexes. Geochem. Intern., 46-54.

Mironova G.D., Zotov A.V., and Gul'ko N.I. (1984) Determination of the solubility of orpiment in acid solutions at $25-150^{\circ} \mathrm{C}$. Geochem. Intern., 53-59.

Mironova G.D., Zotov A.V., and Gul'ko N.I. (1991) The solubility of orpiment in sulfide solutions at $25-150^{\circ} \mathrm{C}$ and the stability of the arsenic sulfide complexes. Geochem.Intern., 61-73.

Naumov G.B., Ryzhenko B.N. and Khodakovsky, I.L. (1974) Handbook of Thermodynamic Data. U.S. Geol. Surv.WRD-74-001, 328 p.

Pan P. and Wood S.A. (1994) Solubility of Pt and Pd sulfides and Au metal in aqueous bisulfide solutions: II. Results at 200 to $350^{\circ} \mathrm{C}$ and saturated vapor pressure. Mineral.Deposita 29, 373390.

Plyasunov A.V., O'Connell J.P., Wood R.H., and Shock E.L., 2000. Infinite dilution partial molar properties of aqueous solutions of nonelectrolytes. II. Equations for the standard thermodynamic functions of hydration of volatile nonelectrolytes over wide ranges of conditions including subcritical temperatures. Geochim. Cosmochim. Acta 64, 2779-2795.

Pokrovski G., Gout R., Schott J., Zotov A., and Harrichoury J. (1996) Thermodynamic and stoichiometry of As (III) hydroxide complexes at hydrothermal conditions. Geochim. Cosmochim. Acta 60, 737-749.

Pokrovski, G.., Roux, J., and Zakirov, I. (2000) Arsenic speciation and transport in hydrothermal vapour and low-density crustal fluids. In Steam, Water and Hydrothermal Systems (eds. Tremain, Gill, Irish, and Balakrishnan) NRC Research Press, Ottawa.

Popova M. Y., Khodakovsky I.L., and Ozerova N.A. (1975) Measurement of the thermodynamic parameters of antimony hydroxo-complexes and hydroxofluoride complexes up to 200 degrees C. Geochem. Intern. 12, 223. 
Reichardt, H. and Bonhoefer, K.F. (1931) uber das Absorptions spektrum von gelostem Quecksilber. Ztschr. Phys. 67, 780-789.

Renders P. J., and Seward T.M. (1989) The stability of hydrosulphido- and sulphido- complexes of $\mathrm{Au}(\mathrm{I})$ and $\mathrm{Ag}(\mathrm{I})$ at $25^{\circ} \mathrm{C}$. Geochim. Cosmochim. Acta 53, 245-253.

Schwarzenbach, G. and Widmer, M. (1963) Die Loslichkeit von Metallsulfiden, I. Schwarzes Quecksilbersulfid. Helv. Chim. Acta 46, 2613-2682.

Schwarzenbach, G. and Widmer, M. (1966) Die Loslichkeit von Metallsulfiden, II. Silbersulfid. Helv. Chim. Acta 49, 111-123.

Seal R.R., Robie R.A., Barton P.B., and Hemingway B.S. (1992) Superambient heat capacities of synthetic stibnite, berthierite, and chalcostibnite: Revised thermodynamic properties and implications for phase equilibria. Econ. Geol. 87, 1911-1918.

Shenberger D.M. and Barnes H.L. (1989) Solubility of gold in aqueous sulfide solutions from 150 to $350^{\circ}$ C. Geoch. Cosmochim. Acta 53, 269-278.

Shikina N.D. and Zotov A.V. (1991) Thermodynamic properties of $\mathrm{Sb}(\mathrm{OH})_{3}{ }^{0}$ up to $723.15 \mathrm{~K}$ and 1000 bar. Geochem. Intern., 97-103.

Shikina N.D. and Zotov A.V. (1999) Solubility of stibnite $\left(\mathrm{Sb}_{2} \mathrm{~S}_{3}\right)$ in water and hydrogen sulfide solutions at temperatures of $200-300^{\circ} \mathrm{C}$ and under vapor-saturated conditions and pressure of 500 bar. Geochem. Intern., 82-86.

Shikina N.D., Zotov A.V., and Khodakovsky, I.L. (1982) An experimental investigation of the equilibria in the $\alpha-\mathrm{HgS}-\mathrm{H} 2 \mathrm{~S}-\mathrm{H} 2 \mathrm{O}$ system at $90^{\circ}$ and $150^{\circ}$. Geochem. Intern. 18, 109-117.

Shock E.L. and Helgeson H.C. (1988) Calculation of the thermodynamic and transport properties of aqueous species at high pressures and temperatures: Correlation algorithms for ionic species and equation of state predictions to $5 \mathrm{~kb}$ and $1000^{\circ}$ C. Geoch. Cosmochim. Acta 52, 20092036. 
Shock, E.L., Helgeson, H.C., and Sverjensky, D.A., 1989. Calculation of the thermodynamic and transport properties of aqueous species at high pressures and temperatures: Standard partial molal properties of inorganic neutral species. Geoch. Cosmochim. Acta 53, 2157-2183.

Shock E.L., Oelkers E.H., Johnson J.W., Sverjensky D.A, and Helgeson H.C. (1992) Calculation of the thermodynamic and transport properties of aqueous species at high pressures and temperatures: Effective electrostatic radii to $1000 \mathrm{C}$ and 5 kb. J. Chem. Soc. London Faraday Trans. 88, 803-826.

Shock E.L., Sassani D.C., Willis M., and Sverjensky D.A. (1997) Inorganic species in geologic fluids: Correlations among standard partial molal thermodynamic properties of aqueous ions and hydroxide complexes. Geoch. Cosmochim. Acta 61, 907-950.

Simon, G., Kesler, S.E., and Chryssoulis, S. (1999) Geochemistry and textures of gold-bearing arsenian pyrite, Twin Creeks, Nevada: Implications for deposition of gold in Carlin-type deposits. Econ. Geol. 94, 405-422.

Sorokin, V.I. (1973) Solubility of mercury in water over the temperature-pressure range $300-500^{\circ} \mathrm{C}$ and 500-1000 atm. Dokl. Akad. Nauk SSSR 213, 852-855.

Sorokin, V.I., Alekhin, Y.V., and Dadze, T.P. (1978) Solubility of mercury in the system $\mathrm{Hg}_{-} \mathrm{H}_{2} \mathrm{O}$, $\mathrm{HgS}-(\mathrm{Cl})-\mathrm{H} 2 \mathrm{O}$ and forms and existence in sulphide-forming waters at Kamchatka and Kunashir Island. In Contributions to Physico-Chemical Petrology VIII (ed. Zharikov), Nauka Press, Moscow, 133-149.

Spycher N.F. and Reed M.H. (1989) As(III) and Sb(III) sulfide complexes; an evaluation of stoichiometry and stability from existing experimental data. Geochim. Cosmochim.Acta 53, 2185-2194.

Sretenskaya N.G. (1977) Dissociation of hydrogen sulfide acid under pressure. Geokhimiya 3, 430438.

Stefansson, A. and Seward, T.M. (2000) Gold(I) sulphide complexing in hydrothermal solutions. Goldschmidt 2000. Oxford, U.K. 
Stranski I.N., Plieth K., and Zoll I. (1958) Über die Auflösung, die Loslichkeit und die Unwandlung der beiden Arsenik Modifikationen in Wasser und wäßrigen Lösungen. Zeit Electrochem. 62, 366-372.

Stock, A., Cucuel, F., Gerstner, F., at al. (1934) Uber Verdampfung, Loslichkeit und Oxydation des metallischen Quecksilber. Ztsche. Anorg. Und Allg. Chem. 217, 241.

Sugaki, A., Scott, S.D., Hayashi, K., and Kitakaze, A. (1987) $\mathrm{Ag}_{2} \mathrm{~S}$ solubility in sulfide solutions up to $250^{\circ} \mathrm{C}$. Geochem. J. 21, 291-305.

Sulemeinov, O.M. and Krupp, R.E. (1994) Solubility of hydrogen sulfide in pure water and in $\mathrm{NaCl}$ solutions, from 20 to $320^{\circ} \mathrm{C}$ and at saturation pressures. Geoch. Cosmochim. Acta 58, 24332444.

Suleimenov O.M. and Seward T.M. (1997) A spectrophotometric study of sulfide ionization in aqueous solutions. Geoch. Cosmochim. Acta 61, 5187-5198.

Sverjensky D.A., Shock E.L. and Helgeson H.C. (1997) Prediction of the thermodynamic properties of aqueous metal complexes to 1000 degrees $\mathrm{C}$ and $5 \mathrm{~kb}$. Geoch. Cosmochim. Acta 61, 13591412.

Tanger J.C. and Helgeson H.C. (1988) Calculation of the thermodynamic and transport properties of aqueous species at high pressures and temperatures: Revised equations of state for the standard partial molal properties of ions and electrolytes. Amer. J. Sci. 288, 19-98.

Tossell J. A. (1994) The speciation of antimony in sulfidic solutions; a theoretical study. Geoch. Cosmochim. Acta 58, 5093-5104.

Tossell J. A. (1996) The speciation of gold in aqueous solution; a theoretical study. Geoch. Cosmochim. Acta 60, 17-29.

Tsonopoulos C., Coulson D.M., and Inman L.B. (1976) Ionization constants of water pollutants. J. Chem. Eng. Data 21, 190-193. 
Wagman D.D., Evans W.H., Parker V.B., Schumm R.H., Halow I., Bailey S.M., Churney K.L., and Nuttall R.L (1982) The NBS tables of chemical thermodynamic properties. Selected values for inorganic and $\mathrm{C} 1$ and $\mathrm{C} 2$ organic substances in SI units. J. Phys. Chem. Ref. Data 11, suppl. 2, $392 \mathrm{p}$.

Webster J. G. (1990) The solubility of $\mathrm{As}_{2} \mathrm{~S}_{3}$ and speciation of As in dilute and sulphide- bearing fluids at 25 and $90^{\circ}$ C. Geoch. Cosmochim. Acta 54, 1009-1017.

Williams-Jones, A.E. and Normand, C. (1997) Controls on mineral paragenesis in the system Fe-SbS-O. Econ. Geol. 92, 308-324.

Wood, S.A., Crerar, D.A., and Borcsik, M.P. (1987) Solubility of the assemblage pyrite-pyrrhotitemagnetite-sphalerite-galena- $\mathrm{CO}_{2}$ solutions from $200^{\circ}$ to $350^{\circ} \mathrm{C}$. Econ. Geol. 82, 1864-1887.

Wood S.A., Pan P, Zhang Y, and Mucci A. (1994) The solubility of Pt and Pd sulfides in bisulfide solutions: I. Results at $25-90^{\circ} \mathrm{C}$ and 1 bar pressure. Mineral. Deposita 29, 309-317.

Yefremova, V.P., Kuznetsov, V.A., and Shikina, N.D. (1982) The solubility of $\alpha-\mathrm{HgS}$ in hydrothermal solutions at elevated temperatures. Geochem. Int. 19, 55-62.

Zakaznova, V.P., Seward, T.M., and Suleimenov, O.M. (2000) Spectrophometric determination of the first ionization constant of $\mathrm{H}_{3} \mathrm{AsO}_{3}$ from 25 to $300^{\circ} \mathrm{C}$. In Steam, Water and Hydrothermal Systems (eds. Tremain, Gill, Irish, and Balakrishnan) NRC Research Press, Ottawa, 694-699.

Zotov A.V. and Baranova N.N. (1995) The solubility of $\mathrm{Au}_{2} \mathrm{~S}$ and $\mathrm{AuAgS}$ in near-neutral sulphide solutions at temperatures of 25 and $80^{\circ} \mathrm{C}$ and pressures of 1 and 500 bars. In Water-Rock Interaction, (eds. Kharaka and Chudaev). pp. 773-776.

Zotov A.V., Baranova N.N., Dar'yina T.G., Bannykh, and Kolotov V.P. (1985) The stability of $\mathrm{Au}(\mathrm{OH})^{0}$ in water at $300-500^{\circ} \mathrm{C}$ and $500-1500$ atm. Geochem. Intern. 5, 156-161.

Zotov, A.V., Shikina, N.D., and Akinfiev, N.N. (2003) Thermodynamic properties of Sb(III) hydroxide complex $\mathrm{Sb}(\mathrm{OH})_{3}(\mathrm{aq})$ at hydrothermal conditions. Geoch. Cosmochim. Acta 67, 1821-1836. 